\title{
Synthetic Methods
}

Recent Advances in the One-Step Synthesis of Distally Fluorinated Ketones

Yuwen Zeng, Chuanfa $\mathrm{Ni}$, and Jinbo $\mathrm{Hu}^{*[\mathrm{a}]}$

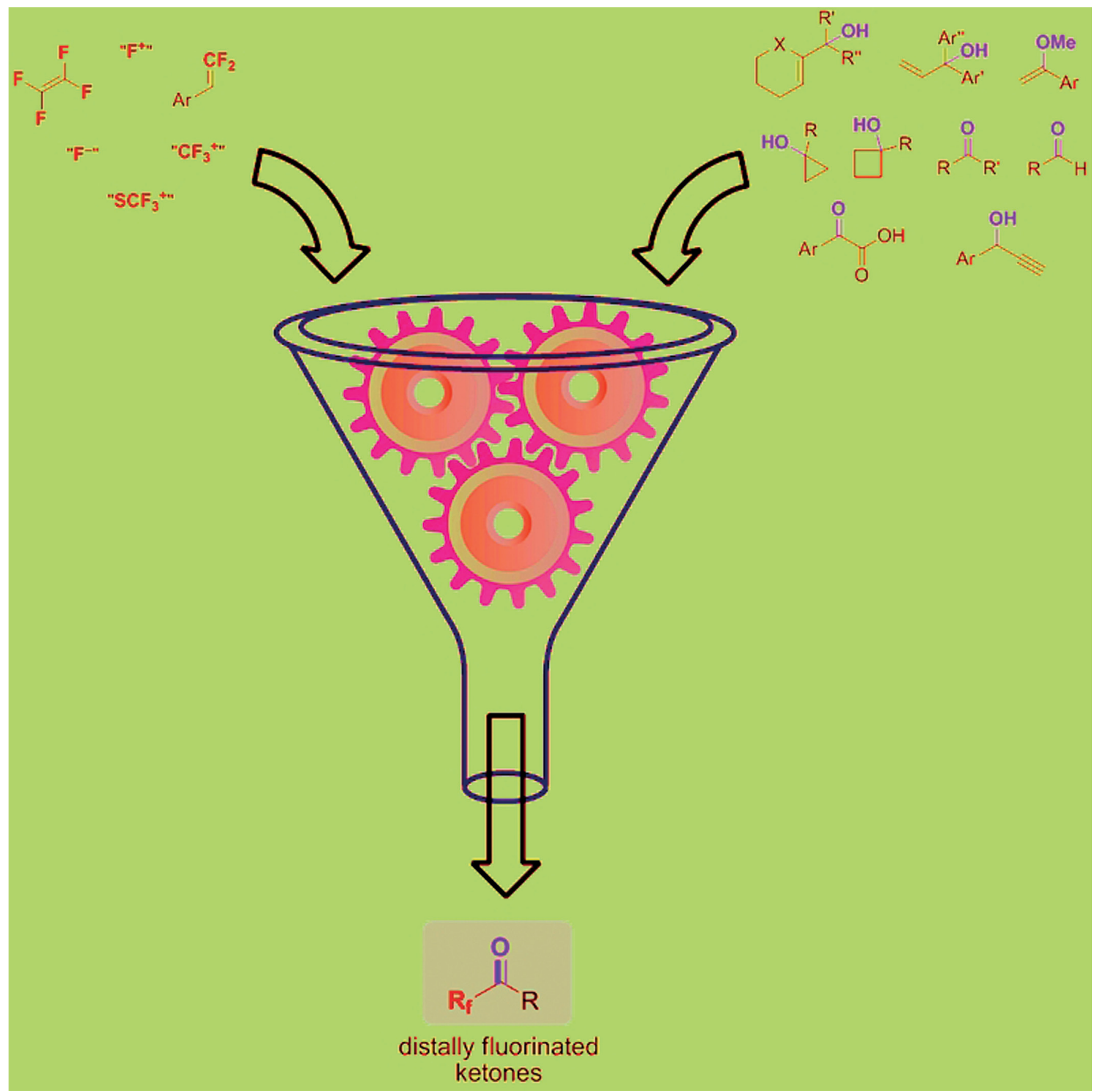


Abstract: Fluorinated ketones are intriguing compounds in synthetic chemistry and life science-related fields. The development of efficient methodologies to obtain these compounds is of significant importance and has therefore attracted considerable attention. This Minireview highlights recent progress made in the synthesis of fluorine-containing ketones, with an emphasis on those methods in which the construction of carbonyl groups is synergetic with distal $(\beta-, \gamma-, \delta-$, etc.) incorporation of fluorine atoms or fluorinated groups.

\section{Introduction}

Fluorine-containing molecules are prevalent in pharmaceuticals, agrochemicals and materials, because the introduction of fluorine atoms or fluorinated moieties can potentially enhance their lipophilicity, metabolic stability, and bioavailability. ${ }^{[1]}$ Among various types of fluoroorganic compounds, fluorinated ketones have attracted considerable attention in synthetic chemistry and life science-related fields. ${ }^{[2]}$ For instance, fluoroalkylated ketones can act as inhibitors for a variety of enzymes $^{[3]}$ or serve as fluorinated synthons ${ }^{[4]}$ (or intermediates) in constructing fluorinated heterocycles ${ }^{[5]}$ and bioactive molecules. ${ }^{[6]}$ Moreover, they have also been used as monomers for polymeric materials, ${ }^{[7]}$ heavy metal scavengers, ${ }^{[8]}$ and chiral catalysts for epoxidation reactions (Scheme 1). ${ }^{[9]}$

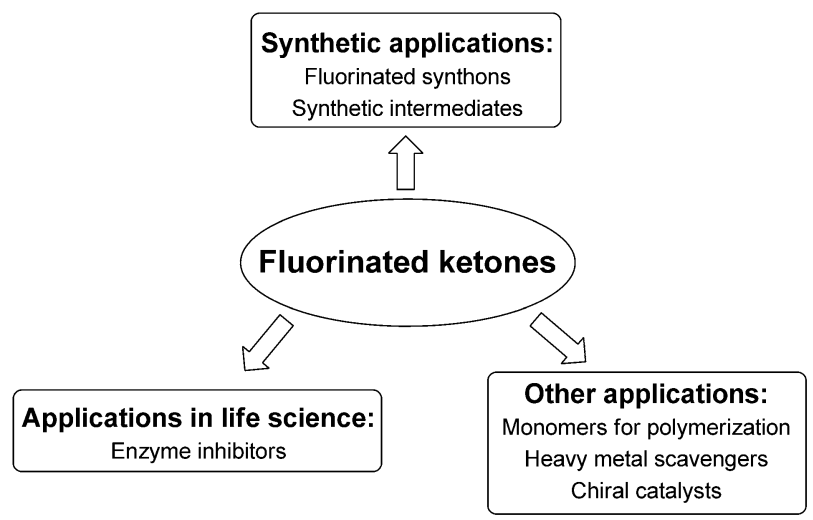

Scheme 1. Applications of fluorinated ketones.

Much effort has been exerted to develop new methods for the synthesis of fluorinated ketones (Scheme 2). Generally, traditional routes to fluorinated ketones could be divided into several categories: 1) Condensation/alkylation reactions using fluorinated compounds as building blocks (Scheme 2a, c, and e) ${ }^{\left[{ }^{[10]}\right.}$ 2) oxidation of fluorinated alcohols (Scheme $2 \mathrm{~b}$ ) ${ }^{[11]}$ 3) nucleophilic or electrophilic fluorination/fluoroalkylation of carbonyl compounds (Scheme $2 \mathrm{~d}$ and i) $i^{[12]}$ 4) Wittig reaction between phosphonium ylides and fluoroacetic derivatives (Scheme $2 \mathrm{f})_{i} i^{[13]} \quad$ 5) electrophilic acylation (Friedel-Crafts

\footnotetext{
[a] Y. Zeng, C. Ni, Prof. Dr. J. Hu

Key Laboratory of Organofluorine Chemistry

Shanghai Institute of Organic Chemistry, Chinese Academy of Sciences

345 Ling-Ling Road, Shanghai 200032 (P. R. China)

E-mail:jinbohu@sioc.ac.cn
}

reaction; Scheme $2 \mathrm{~g}){ }_{i}^{[14]}$ 6) rearrangement of fluorinated compounds (Scheme $2 \mathrm{~h}$ ). ${ }^{[15]}$

Despite considerable developments being attained in the realm of fluorinated ketone synthesis, prominent limitations remain. On the one hand, these methods are generally limited to the synthesis of structurally simple fluorinated ketones. As carbonyl and fluorinated groups are introduced stepwise, the synthetic efficiency could be very low for complex target molecules. On the other hand, although traditional methods mentioned above are applicable to $\alpha$-fluoro/fluoroalkyl ketone synthesis, ${ }^{[16]}$ the synthesis of distally fluorinated ketones (such as $\beta-, \gamma-$ and $\delta$-fluoro/fluoroalkyl ketones) are still challenging. Thus, efficient and straightforward protocols for fluorinated ketones, especially for distally fluorinated ketones, are of high synthetic importance.

To address these limitations, recent efforts have been directed towards developing more facile and concise routes to distally fluorinated ketones. An introduction of these important advances to the synthetic community would be timely. In this Minireview, we highlight recent breakthroughs in this field, with an emphasis on those methods that feature in situ introduction of the fluorinated moiety and carbonyl group in a single-step or one-pot process, that afford efficient access to distally $(\beta-, \gamma-, \delta-$, etc.) fluorinated ketones, and that are suitable for the synthesis of complex molecules and natural product analogues.

\section{One-Step Syntheses of Distally Fluorinated Ketones}

\subsection{Trifluoromethylation/fluorination-initiated 1,2-migration of allylic alcohols}

$\beta$-Trifluoromethyl ketones are difficult to prepare because direct nucleophilic trifluoromethylation of $\alpha, \beta$-unsaturated ketones typically undergo 1,2-addition rather than 1,4-addition, affording trifluoromethyl allylic alcohols. ${ }^{[17]}$ Although in some particular cases, 1,4-nucleophilic trifluoromethylation could be achieved, ${ }^{[18]}$ direct 1,4-addition of $\mathrm{CF}_{3}{ }^{-}$anion to conventional $\alpha, \beta$-unsaturated ketones has rarely been reported, presumably due to the hardness of the $\mathrm{CF}_{3}$ group. ${ }^{[19]}$

To solve this problem, indirect synthetic routes have been developed. $\alpha, \alpha$-Disubstituted allylic alcohols are useful precursors in rearrangement reactions such as semipinacol rearrangement $^{[20]}$ and neophyl rearrangement ${ }^{[21]}$ (Scheme 3). In these reactions, substrates can be activated by cations or radicals, then undergo a 1,2-migration to give corresponding $\alpha, \beta$-disubstituted ketones. Notably, for unsymmetrical $\alpha, \alpha$-diaryl allylic alco- 
hols, electron-rich aryl groups migrate preferentially in a cationic (semipinacol) pathway, ${ }^{[22]}$ while electron-deficient aryl groups migrate preferentially in a radical (neophyl) pathway. ${ }^{[21 c]}$

In 2013, Wu, Li and co-workers developed a copper-catalyzed trifluoromethylation-initiated neophyl rearrangement of $\alpha, \alpha$-diaryl allylic alcohols (Scheme 4). ${ }^{[23 a]}$ Both symmetrical and unsymmetrical $\alpha, \alpha$-diaryl allylic alcohols can undergo this rearrangement, affording corresponding $\alpha$-aryl $\beta$-trifluoromethyl ketones in moderate to good yields. In this reaction, the electron-deficient aryl group migrates preferentially over the electron-rich aryl group, indicating that this rearrangement occurs through a neophyl rearrangement (radical 1,2-aryl migration). Moreover, a preferential migratory aptitude of non-ortho-substituted aryl groups over ortho-substituted ones was observed and this aptitude was further supported by authors' DFT calculations for the radical 1,2-aryl migration (Scheme 4).

Shortly thereafter, another copper-catalyzed trifluoromethylation/1,2-migration of allylic alcohols was reported by Tu and co-workers (Scheme 5). ${ }^{[23 b]}$ In this reaction, a series of $\alpha$-quaternary $\beta$-trifluoromethyl ketones were obtained in moderate yields. Moreover, both aryl groups and alkyl groups could undergo this 1,2-migration. The more electron-deficient aryl group was found to migrate preferentially in unsymmetrical $\alpha, \alpha$-diaryl allylic alcohols, with the expectation of a radical (neophyl) rearrangement. However, when an aryl- and alkylsubstituted allylic alcohol was tested, the more electron-rich aryl-migrated product was obtained exclusively. Therefore, both cationic (Scheme 6, path a) and radical (Scheme 6, path b) pathways were possible after the initial trifluoromethylation process. ${ }^{[24]}$

The semipinacol rearrangement strategy is also applicable to the synthesis of $\beta$-fluoroketones, which are difficult to synthesize by traditional methods. ${ }^{[25]}$ In 2005, Tu and co-workers reported a noncatalytic asymmetric fluorination/semipinacol rearrangement reaction, in which racemic allylic alcohols were converted into $\alpha$-quaternary $\beta$-fluoro aldehydes. ${ }^{[26]}$ Seven years later, Tu and co-workers demonstrated that by using more reactive substrates (2-oxaallylic alcohols) and less reactive fluorination reagent [ $N$-fluorobenzenesulfonimide (NFSI)] in the presence of hydroquinidine-2,5-diphenyl-4,6-pyrimidinediyl diether $\left[(\mathrm{DHQD})_{2} \mathrm{PYR}\right]$, this transformation could proceed in a catalytic manner and be used in the synthesis of chiral $\beta$-fluoroketones (Table 1). ${ }^{[27]}$ To minimize side reactions and improve the enantioselectivity, NFSI was added in several portions. All substrates tested under these conditions afforded the desired products in moderate to good yields with moderate to excellent ee values (Table 1, Condition A). When (DHQD) 2 PYR was replaced by hydroquinine-2,5-diphenyl-4,6-pyrimidinediyl diether $\left[(\mathrm{DHQ})_{2} \mathrm{PYR}\right]$, the products were obtained in moderate yields with slightly lower ee values (Table 1, Condition B).

\subsection{Fluorinative cross-coupling of two olefins}

In most organofluorine coupling reactions, perfluoroalkyl $\left(R_{F}\right)$ groups are usually present in one of starting materials; only in a few examples have these perfluorinated groups been generated from the difluorocarbene and various fluoride sources. ${ }^{[28]}$
These examples represent a distinct perfluoroalkylation strategy, which could be used in the preparation of $\left[{ }^{18} \mathrm{~F}\right] \mathrm{R}_{\mathrm{F}}$ compounds for positron emission tomography (PET) imaging. ${ }^{[28 d]}$ However, this in situ generation concept had not previously been reported for the synthesis of fluorinated ketones. In 2015, our group disclosed an AgF-mediated fluorinative cross-coupling reaction of two olefins (Scheme 7). ${ }^{[29]}$ By combining the in situ generation of the $\mathrm{CF}_{3}$ motif and the radical coupling with $\alpha$-methoxystyrene derivatives in a single reaction system, $\beta$-trifluoromethyl ketones were readily obtained, after rapid hydrolysis, in moderate to good yields. Ester, tosyl, sulfonyl, nitro, and cyano groups were tolerated during both the coupling process and the mild hydrolysis process. It should be noted that the heteroaryl substrate 2-(1-methoxyvinyl)pyridine was also a good coupling partner in this transformation, affording the corresponding ketone in satisfactory yield (64\%).

On the basis of mechanistic studies and previous work, ${ }^{[30]}$ a reaction pathway was proposed (Scheme 8 ). Initially, in the

Yuwen Zeng received his Ph.D. degree in 2015 from the Shanghai Institute of Organic Chemistry, Chinese Academy of Sciences (SIOC, CAS) under the supervision of Prof. Jinbo Hu, focusing on the development of synthetic methods for fluorination and fluoroalkylation of arynes. He is currently a research assistant at the CAS Key Laboratory of Organofluorine Chemistry, SIOC, working on novel fluorination reagents.

Chuanfa Ni obtained his PhD degree in chemistry from SIOC, CAS in 2009 under the supervision of Professor Jinbo Hu. After his postdoctoral work (2009-2012) at the University of Southern California under the supervision of Professor G. K. Surya Prakash, he joined SIOC as an associate research professor. His research interests lie in the development of new methodologies for the synthesis of fluorinated molecules.

Jinbo $\mathrm{Hu}$ received a PhD from the University of Southern California (USC, Los Angeles, USA) under the guidance of Professors G. K. Surya Prakash and George A. Olah. After postdoctoral study at USC, he accepted a Research Professorship at SIOC, CAS in 2005, where he is currently serving as the Head of CAS Key Laboratory of Organofluorine Chemistry. He was the recipient of RSC Fluorine Prize 2009 and the Tan Kah-Kee Youth Science Award 2012. His research interest lies in selective fluorination and fluoroalkylation methodologies and in fluorinated materials.
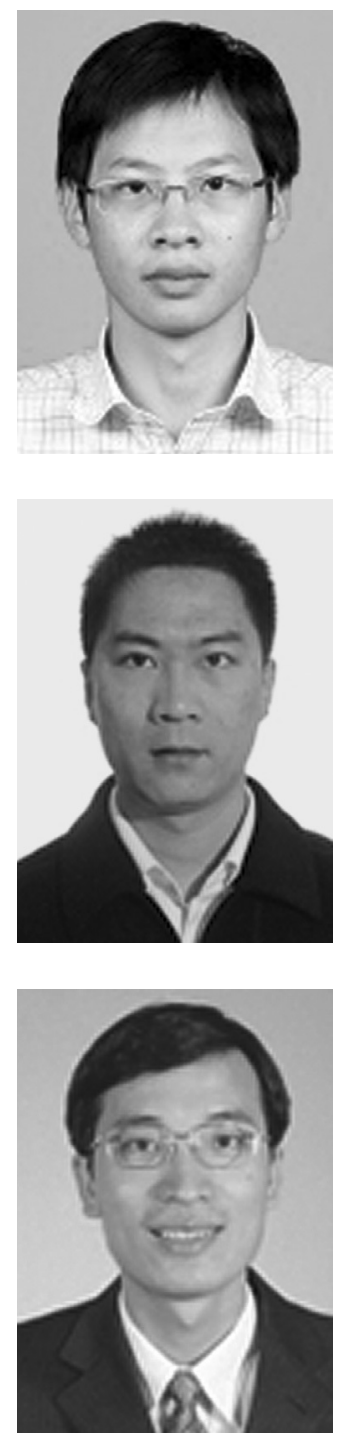


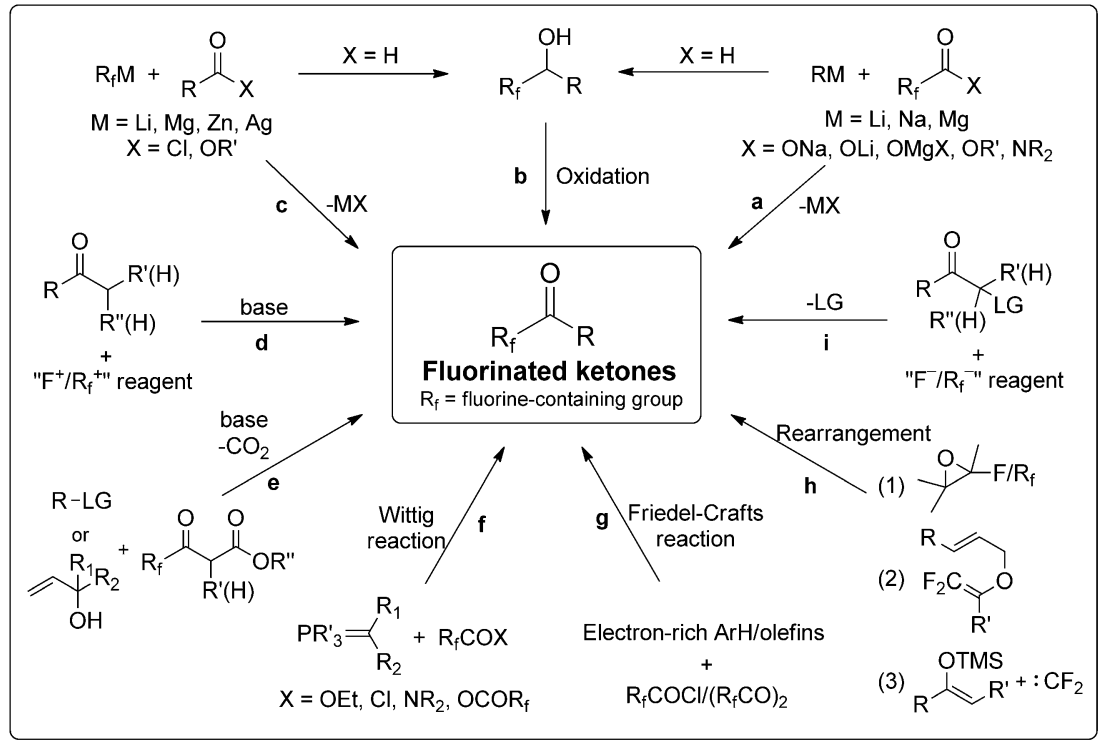

Scheme 2. Traditional approaches to fluorinated ketones.

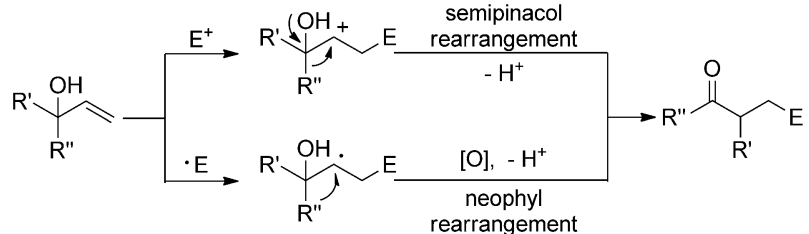

Scheme 3. Semipinacol and neophyl rearrangements of $\alpha, \alpha$-disubstituted allylic alcohols.

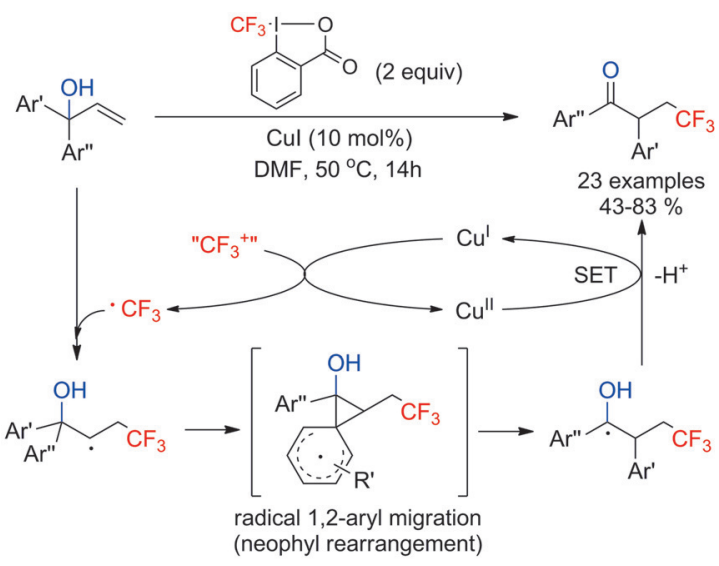

Scheme 4. Copper-catalyzed trifluoromethylation-initiated neophyl rearrangement of $\alpha, \alpha$-diaryl allylic alcohols.

presence of $\mathrm{AgF}$, the gem-difluoroolefin is converted into a $\alpha$ trifluoromethyl benzylsilver intermediate (step a), which undergoes rapid $\mathrm{C}-\mathrm{Ag}$ bond homolysis to afford a $\alpha$-trifluoromethyl benzyl radical and $\mathrm{Ag}^{0}$ (step b). Further cross-coupling of this benzylic radical and the non-fluorinated olefin forms a new carbon-centered radical (step c), which is oxidized and deprotonated by 2 equivalent of $\mathrm{AgF}$ to give the $\alpha$-trifluoromethyl

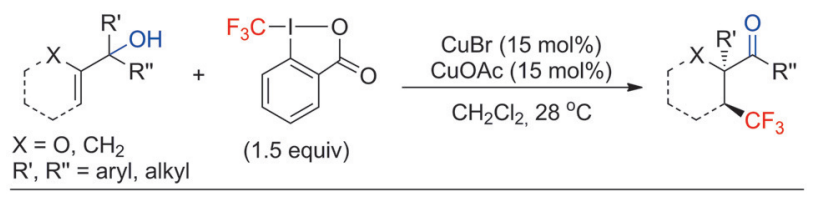

$x$<smiles>[X]c1ccccc1</smiles><smiles>[X]c1ccc(C2(C(=O)C=C)OCCCC2C)cc1</smiles>

$\mathrm{X}=\mathrm{H}, 64 \%$

$X=M e, 61 \%$

$\mathrm{X}=\mathrm{F}, 64 \%$

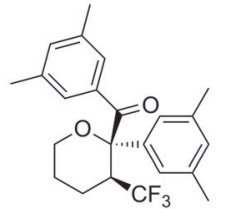

$35 \%$

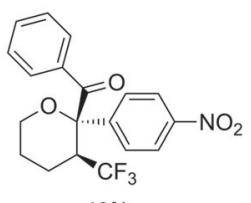

$40 \%$

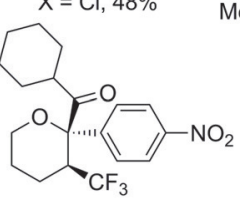

$63 \%$<smiles>[R]C1(C(=O)c2ccc(OC)cc2)OCCC[C@H]1C(F)(F)F</smiles><smiles>[X]C12CCCCC1[C@H](C(F)(F)F)CCC2</smiles><smiles>COc1ccc(C(C)(CC(F)(F)F)C(=O)C2CCCCC2)cc1</smiles>

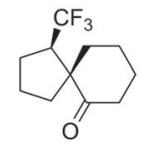

$60 \%$
$66 \%$

$\mathrm{R}=\mathrm{Me}, 65 \%$
$\mathrm{R}=\mathrm{Et}, 63 \%$

$X=0,70 \%$

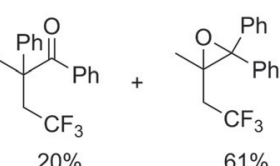

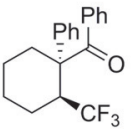

$36 \%$
Scheme 5. Copper-catalyzed trifluoromethylation/1,2-migration of allylic alcohols.

alkene (steps $d$ and e). Finally, the hydrolysis of the newly formed alkene releases the corresponding $\beta$-trifluoromethyl ketone (step f). It is therefore worth noting that AgF plays several roles in this reaction: 1) Affording the $\alpha$-trifluoromethyl benzylsilver intermediate by synergetic addition to the gem-difluoroolefin; 2) oxidizing the carbon radical to give the carbocation; 3 ) serving as a base to regenerate the double bond by 


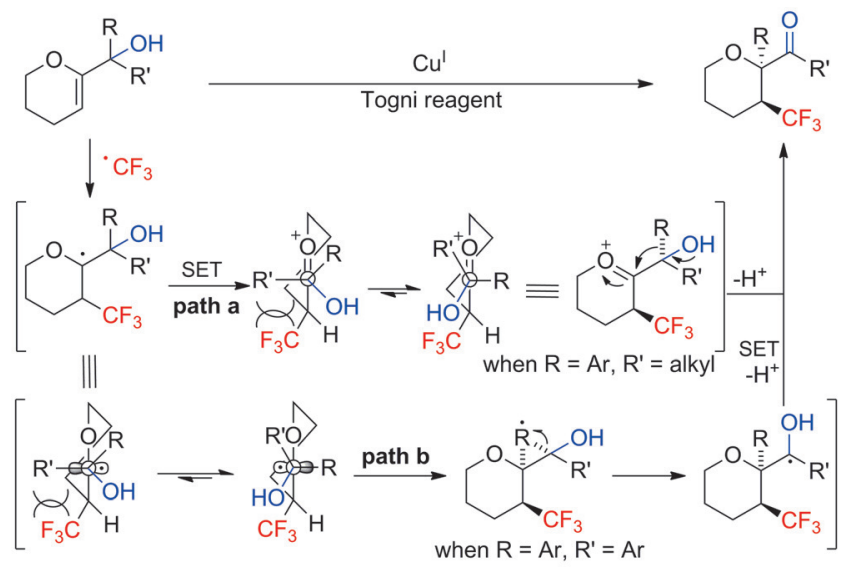

Scheme 6. Proposed mechanism for different substrates.

removing the proton. These roles could also explain why an excess amount of $\mathrm{AgF}$ (3.0 equiv) is needed in this process.

\subsection{Trifluoromethylative rearrangement of propargylic alcohols}

Propargylic alcohols are useful and readily available intermediates in organic synthesis. These compounds can undergo Meyer-Schuster rearrangement to generate active allenols, which can be trapped by various electrophiles to give $\alpha$-substituted enones. ${ }^{[31 a, b]}$ Encouraged by these results, Liu and coworkers developed a domino copper-catalyzed Meyer-Schuster rearrangement/trifluoromethylation reaction, furnishing corresponding $\alpha$-trifluoromethyl enones (Scheme 9). ${ }^{[32]}$ Both the electronic properties and positions of the substituents had an essential effect on reactivity, giving products with moderate to good yields. Interestingly, cyclic alcohols were tolerated in this transformation. Furthermore, these $\alpha$-trifluoromethyl enones could be trapped by hydroxylamine or hydrazine to provide important trifluoromethylated heterocyclic motifs (isoxazole and pyrazole, respectively) in a one-pot operation.

In light of control experiments and previous investigations, ${ }^{[31]}$ Liu proposed a mechanism (Scheme 10), in which two possible pathways may be involved after the initial coppercatalyzed Meyer-Schuster rearrangement. In path a, the active allenol intermediate $\mathbf{A}$ interacts directly with the $\mathrm{CF}_{3}$ radical, leading to an enone with the $\mathrm{CF}_{3}$ group trans to $\mathrm{R}^{\prime}$ ( $E$-selective isomer) as the active electrophilic $\mathrm{CF}_{3}$ radical should approach the enolic double bond from the less hindered face. In path $b$, the favored copper-containing intermediate $\mathbf{B}^{[31, d]}$ was generated to yield a product with the $\mathrm{CF}_{3}$ group cis to $\mathrm{R}^{\prime}$ ( $Z$-selective isomer). On the basis of the experimental results with preferred E-selectivity, the author concluded that path a might be the predominant process.

Another recent example of trifluoromethylative rearrangement of propargylic alcohols was reported by Park, Cho, and Joo (Scheme 11). ${ }^{[33]}$ In their method, terminal propargylic alcohols underwent visible light-induced hydrotrifluoromethylation to afford trifluoromethylated allylic alcohols $\mathbf{2}$. The subsequent radical process for allylic isomerization generated the trifluoromethylated enol species 3, which underwent tautomerization

Table 1. Organocatalytic asymmetric fluorination/semipinacol rearrangement of allylic alcohols.



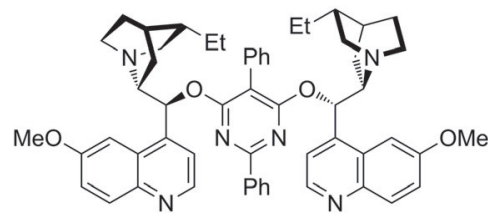

$(\mathrm{DHQD})_{2} \mathrm{PYR}$

Entry Substrate

$$
\begin{aligned}
& n=1, \mathrm{R}=\mathrm{C}_{6} \mathrm{H}_{5}, \mathrm{R}^{\prime}=\mathrm{H} \\
& n=1, \mathrm{R}=\mathrm{C}_{6} \mathrm{H}_{5}, \mathrm{R}^{\prime}=\mathrm{H} \\
& n=1, \mathrm{R}=4-\mathrm{FC}_{6} \mathrm{H}_{4}, \mathrm{R}^{\prime}=\mathrm{H} \\
& n=1, \mathrm{R}=4-\mathrm{ClC}_{6} \mathrm{H}_{4}, \mathrm{R}^{\prime}=\mathrm{H} \\
& n=1, \mathrm{R}=4-\mathrm{BrC}_{6} \mathrm{H}_{4}, \mathrm{R}^{\prime}=\mathrm{H} \\
& n=1, \mathrm{R}=3-\mathrm{FC}_{6} \mathrm{H}_{4}, \mathrm{R}^{\prime}=\mathrm{H} \\
& n=1, \mathrm{R}=3,5-\left(\mathrm{CH}_{3}\right)_{2} \mathrm{C}_{6} \mathrm{H}_{3}, \mathrm{R}^{\prime}=\mathrm{H} \\
& n=1, \mathrm{R}=2-\text { naphthyl, } \mathrm{R}^{\prime}=\mathrm{H} \\
& n=1, \mathrm{R}=2-\text { thienyl, } \mathrm{R}^{\prime}=\mathrm{H} \\
& n=1, \mathrm{R}=\mathrm{C}_{6} \mathrm{H}_{5}, \mathrm{R}^{\prime}=\mathrm{Me} \\
& n=0, \mathrm{R}=\mathrm{C}_{6} \mathrm{H}_{5}, \mathrm{R}^{\prime}=\mathrm{H} \\
& n=0, \mathrm{R}=4-\mathrm{FC}_{6} \mathrm{H}_{4}, \mathrm{R}^{\prime}=\mathrm{H}
\end{aligned}
$$

$$
(\mathrm{DHQ})_{2} \mathrm{PYR}
$$<smiles>CCC1C2CCN1C[C@H]2C(Oc1nccc(-c2ccccc2)n1)c1ccnc2ccc(OC)cc12</smiles>

Condition A Yield [\%]

\begin{tabular}{ll}
\multicolumn{2}{c}{ Condition A } \\
Yield [\%] & ee [\%] \\
\hline 6 & 93 \\
3 & 92 \\
4 & 92 \\
9 & 79 \\
1 & 71 \\
6 & 93 \\
4 & 66 \\
6 & 71 \\
7 & 38 \\
6 & 86 \\
8 & 85 \\
\hline
\end{tabular}

\author{
[\%]
}

Condition B

56

34

41

76

54

76

47

66

48

Yield [\%] ee [\%]

[a] Using 0.1 equivalent of catalyst; [b] reaction was carried out at $0{ }^{\circ} \mathrm{C}$. 


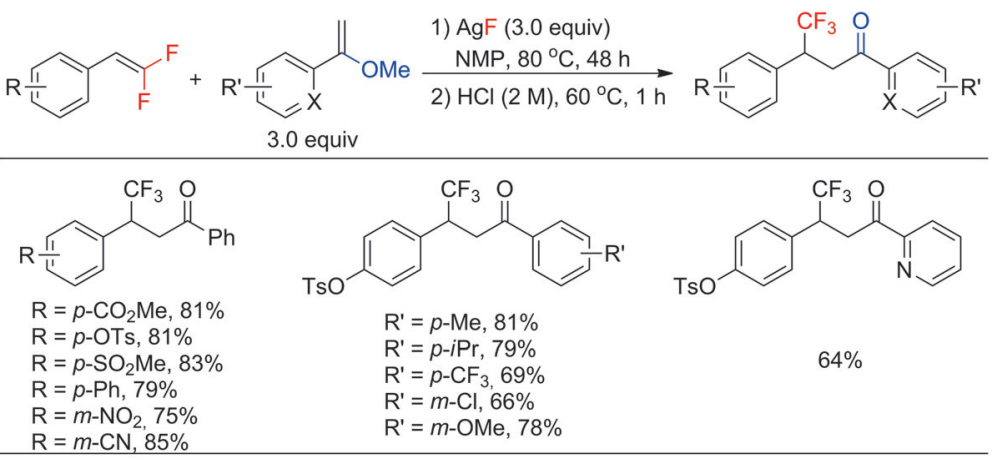

Scheme 7. AgF-mediated fluorinative cross-coupling reaction of two olefins.

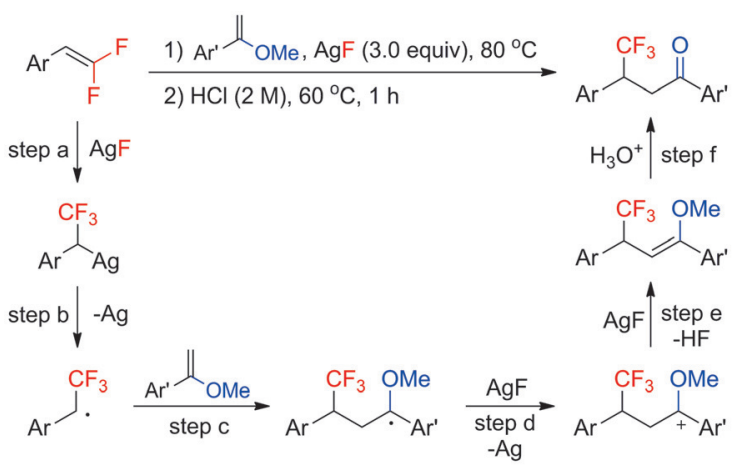

Scheme 8. Proposed mechanism of AgF-mediated fluorinative crosscoupling reaction.

to give the final $\beta$-trifluoromethylated ketones products. One limitation of this method is that only aryl-substituted propargylic alcohols can undergo this isomerization to ketones. Furthermore, internal propargyl alcohols were not good substrates for this procedure, as their reactions generated a mixture of products.

\subsection{Radical carbofluorination of alkenes}

The efficient construction of $\mathrm{C}-\mathrm{F}$ bonds has long been one of the most important aims in organofluorine chemistry. In the past few years, significant progress has been achieved in the transition metal-mediated $\mathrm{C}\left(\mathrm{sp}^{2}\right)-\mathrm{F}$ bond formation. ${ }^{[34]}$ In contrast, the construction of $\mathrm{C}\left(\mathrm{sp}^{3}\right)-\mathrm{F}$ bonds has been somewhat less explored. Some recent breakthroughs come from radical fluorination at specific sites, such as allylic, benzylic, and vinylic positions. ${ }^{[35]}$ However, the radical fluorination strategy has not been employed in the synthesis of fluorinated ketones. Given that $\alpha$-fluorination of ketones is accomplished easily through reaction with electrophilic fluorinating agents, whereas selective fluorination at distal positions remains a challenging task, radical fluorination would be a promising approach, as this strategy could provide new synthetic routes to homofluorinated ketones.

Inspired by the great success of radical-mediated fluorination of unsaturated carbon-carbon bonds, ${ }^{[35 a-e]}$ Duan and coworkers developed a mild silver-catalyzed decarboxylative acylfluorination of styrenes for the synthesis of $\beta$-fluorinated 3-aryl ketones (Scheme 12). ${ }^{[36]}$ In this reaction, both electron-rich and electron-deficient aryloxoacetic acids afford the desired prod-

Condition A:

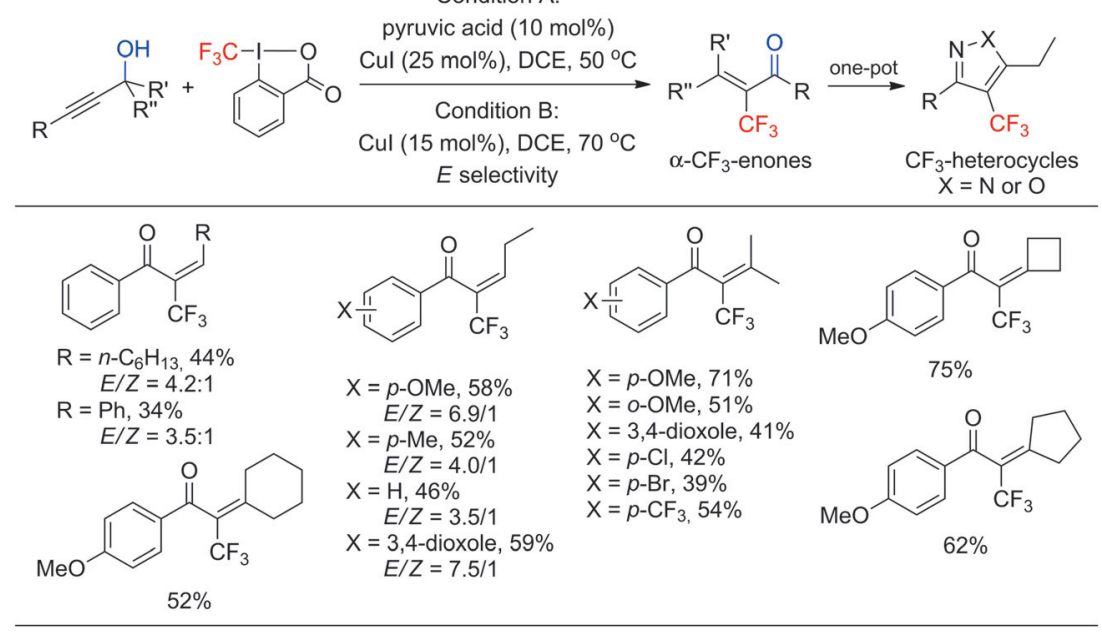

Scheme 9. Copper-catalyzed Meyer-Schuster rearrangement/trifluoromethylation. 


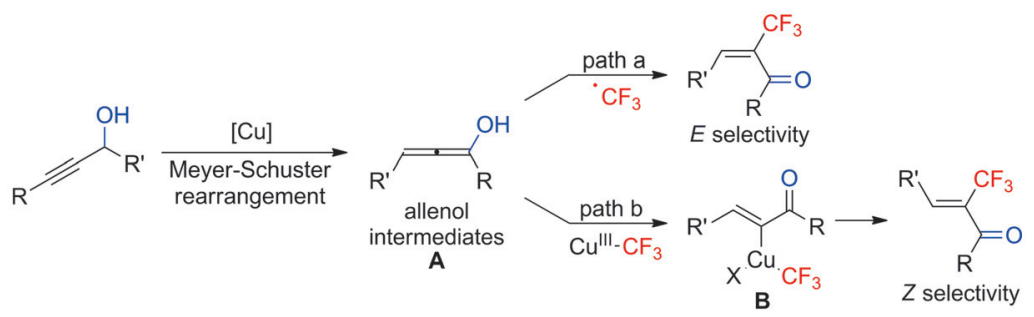

Scheme 10. Proposed mechanism of copper-catalyzed Meyer-Schuster rearrangement/trifluoromethylation.

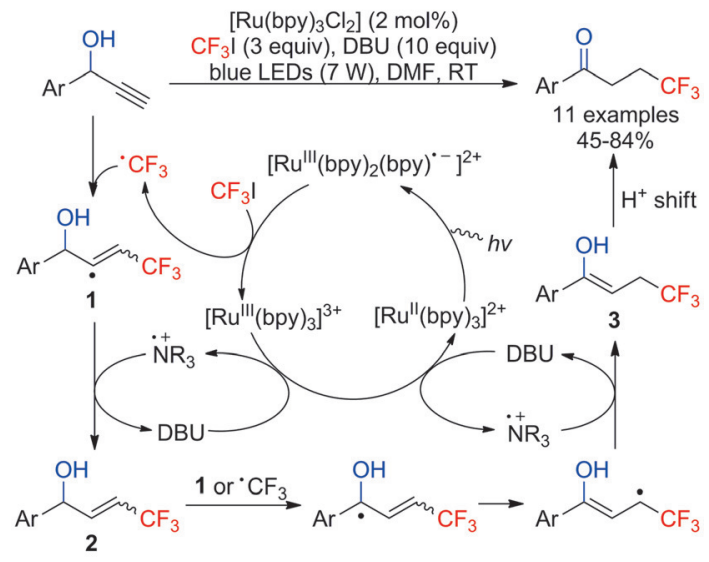

Scheme 11. Visible light-induced trifluoromethylation-isomerization of propargylic alcohols. DBU =1,8-diazabicyclo[5.4.0]-7-undecene.

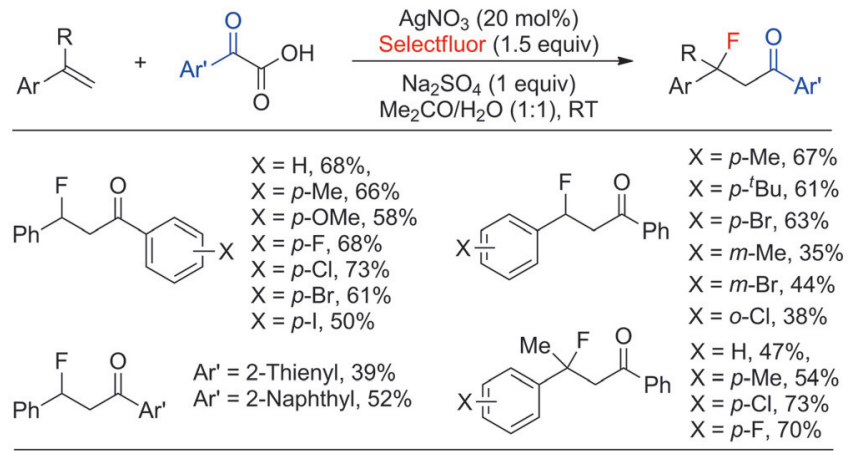

Scheme 12. Silver-catalyzed decarboxylative acylfluorination of styrenes.

ucts in moderate to good yields. Moreover, $\alpha$-methylstyrenes are also good substrates for this transformation, giving rise to the corresponding $\beta$-fluorinated 3-aryl ketones in moderate yields. However, aliphatic terminal alkenes are not compatible in this reaction.

Based on mechanistic studies and previous research by the groups of Kochi ${ }^{[37]}$ and $\mathrm{Li}^{[38]}$ Duan proposed a plausible mechanism (Scheme 13). ${ }^{[36]}$ Firstly, the oxidation of $\mathrm{Ag}^{\prime}$ by Selectfluor gives rise to an $\mathrm{Ag}^{\text {III-}} \mathrm{F}$ intermediate. The subsequent oxidative decarboxylation of $\alpha$-keto acids by this $A g^{\text {III }}-\mathrm{F}$ intermediate affords an $A g^{\prime \prime}-\mathrm{F}$ species and the corresponding nucleophilic acyl radicals. These acyl radicals react with styrenes to generate

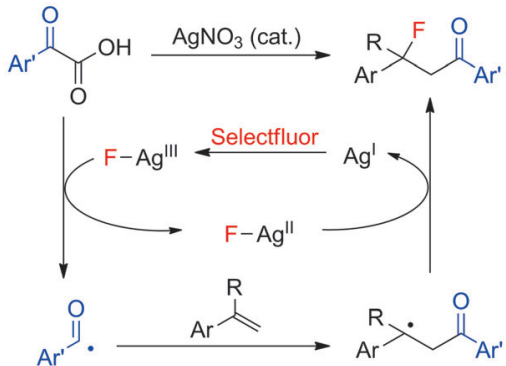

Scheme 13. Proposed mechanism of silver-catalyzed decarboxylation acylfluorination of styrenes.

benzylic radicals, which undergo fluorine atom transfer to provide $\beta$-fluorinated ketones and regenerate the $\mathrm{Ag}^{\prime}$ catalyst.

This radical carbofluorination strategy can also be used in $\gamma$ fluorinated ketone synthesis. $\mathrm{Li}$ and co-workers developed a silver-catalyzed carbofluorination of unactivated alkenes with ketones in aqueous solution (Scheme 14) ${ }^{[39]}$ Both mono- and disubstituted alkenes exhibited high reactivities (Scheme 14, Condition A). When acetone was used as both the substrate and the co-solvent, even trisubstituted alkenes could undergo this transformation (Scheme 14, Condition B). Functional groups such as free carboxylic acid, unprotected hydroxy, and primary alkyl bromide were well tolerated. Moreover, other cy-

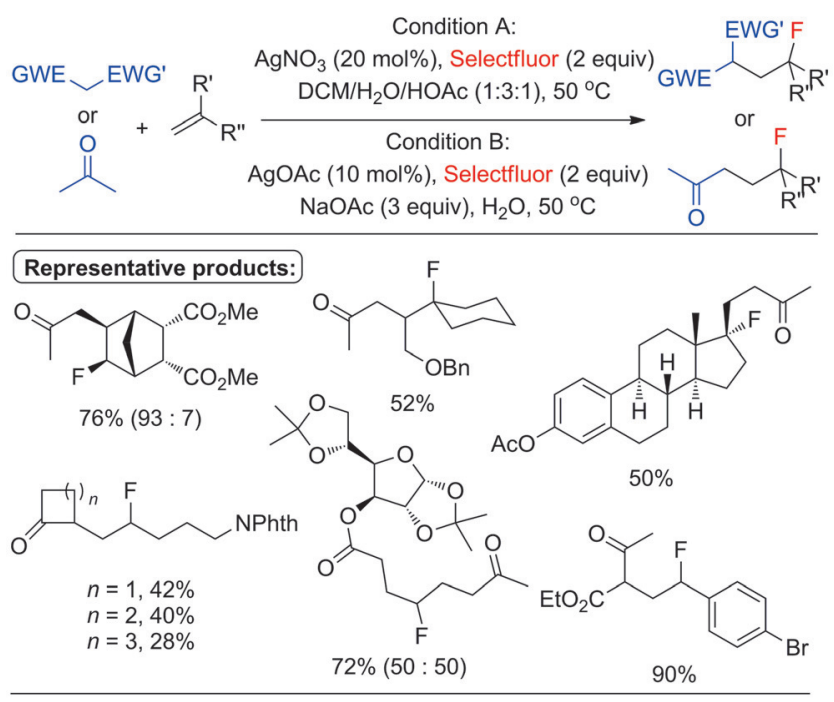

Scheme 14. Silver-catalyzed carbofluorination of unactivated alkenes. 
cloalkanones were also applicable to this protocol. Remarkably, this method could also be used in direct modification of complex molecules (Scheme 14). ${ }^{[39]}$

It was proposed that during the reaction course, the singleelectron oxidation of acetone with the $\mathrm{Ag}^{\mathrm{III}}-\mathrm{F}$ intermediate $\mathrm{e}^{[38]}$ gives rise to an acetonyl radical cation ${ }^{[40]}$ and an $\mathrm{Ag}^{\prime \prime}-\mathrm{F}$ intermediate (Scheme 15). The subsequent deprotonation of the acetonyl radical cation affords an electrophilic carbonyl radical, which further reacts with unactivated alkenes to give another alkyl radical. This nucleophilic radical abstracts a fluorine atom from the $A g^{\prime \prime}-\mathrm{F}$ species to generate the carbofluorination product and the $\mathrm{Ag}^{\prime}$ catalyst.

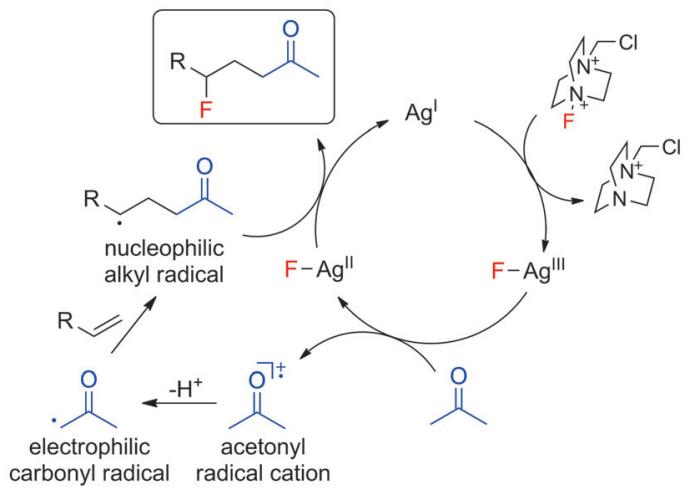

Scheme 15. Proposed mechanism of silver-catalyzed carbofluorination of unactivated alkenes.

\subsection{Ring-opening fluorination/fluoroalkylation of cyclopropanols and cyclobutanols}

Cyclopropanols are versatile intermediates in organic synthesis. These highly strained compounds can be readily prepared by Kulinkovich reactions ${ }^{[41]}$ and can serve as equivalents of homoenolate anions, ${ }^{[42]}$ as well as $\beta$-keto radical precursors ${ }^{[43]}$ under single-electron oxidation conditions (Scheme 16). These characteristics, combined with the fact that other $\beta$-halide $(\mathrm{Br}, \mathrm{I})$ ketone analogues have been obtained by the same ring-opening strategy, ${ }^{[44]}$ also render cyclopropanols potential substrates for radical fluorination.

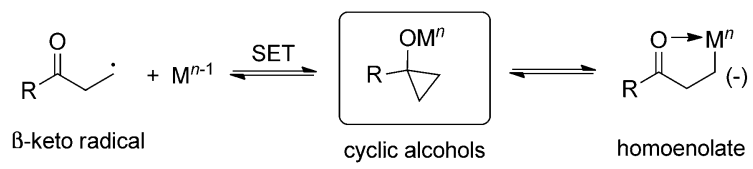

Scheme 16. Reactivity patterns of cyclopropanols.

Recently, Zhu and co-workers reported a silver-catalyzed ring-opening strategy for the synthesis of distal ( $\beta$ - and $\gamma$-) fluorinated ketones (Scheme 17). ${ }^{[4]}$ In this reaction, cyclopropanols were transformed into $\beta$-fluorinated ketones in a concentrated biphasic solution at room temperature (Scheme 17a). Both electron-rich and electron-deficient 1-arylcyclopropanols underwent this transformation smoothly, affording $\beta$-fluorinat-
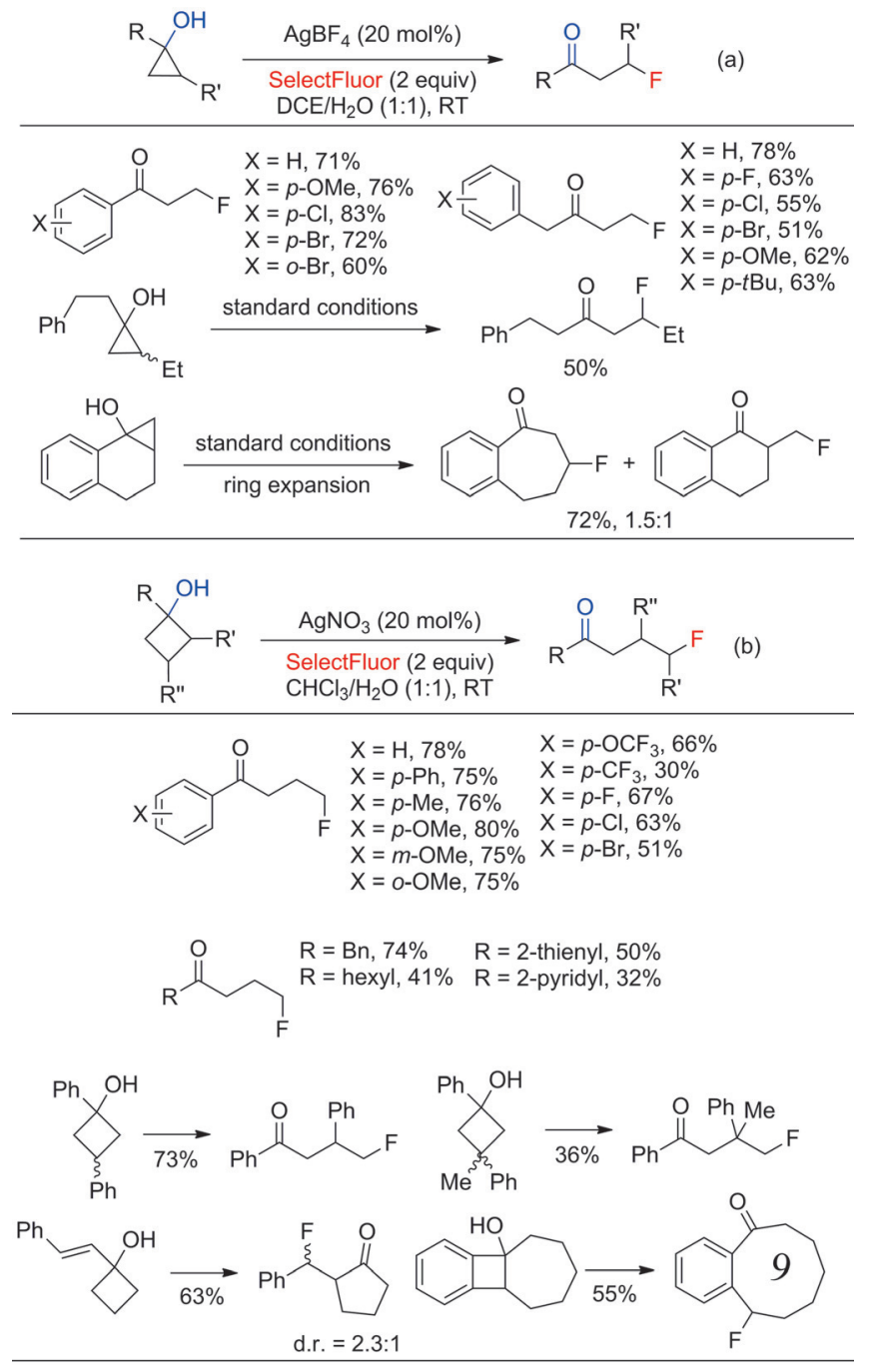

Scheme 17. Synthesis of $\beta$ - and $\gamma$-fluorinated ketones.

ed products in moderate to good yields. Moreover, 1-alkylcyclopropanols with different substituents were also suitable substrates. It should be noted that when 1,2-dialkyl substituted cyclopropanol was employed in this transformation, the fluorination happened exclusively at the tertiary rather than the secondary carbon. Remarkably, fused bicyclic substrates give rise to corresponding ring-expanded fluoroketone products in useful yields.

This ring-opening protocol is also applicable to cyclobutanols, providing $\gamma$-fluoroketones in moderate to good yields (Scheme $17 \mathrm{~b}$ ). However, the reactivities of cyclobutanols are generally lower than their cyclopropanol counterparts and this reaction usually requires a prolonged reaction time.

To gain further insight into this ring-opening/fluorination reaction, a series of experiments were conducted. ${ }^{[45]}$ When the single diastereomer $\mathbf{1}$ a was subjected to the standard reaction conditions, the configuration of the fluorinated carbon center in the product was not retained, which might suggest a radical pathway (Scheme 18a). This hypothesis was further supported by a radical trapping experiment, in which the addition of 2 equivalents of TEMPO completely suppressed the formation 


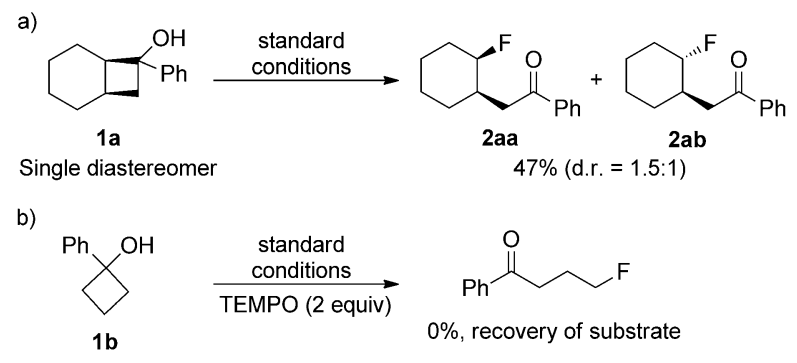

Scheme 18. Mechanistic studies of silver-catalyzed ring-opening fluorination reactions.

of fluorinated products (Scheme 18b). Based on these results, a mechanism was proposed (Scheme 19). Firstly, cyclic alcohols coordinate to $\mathrm{Ag}^{\prime}$ to give complex $\mathrm{A}$, which is oxidized by Selectfluor to generate $\mathrm{Ag}^{\mathrm{III}}-\mathrm{F}$ complex $\mathbf{B}$. Homolysis of this intermediate affords oxy radical $\mathrm{C}$ and an $\mathrm{Ag}{ }^{\prime \prime}-\mathrm{F}$ species. Oxy radical C undergoes ring-opening to generate alkyl radical $\mathbf{D}$, which reacts with the $\mathrm{Ag}^{\prime \prime}-\mathrm{F}$ species to afford the fluorinated product and releases the $\mathrm{Ag}^{\prime}$ catalyst.

Shortly thereafter, the groups of Murakami, ${ }^{[46]}$ Lectka $_{r}^{[47]}$ and Loh $^{[48]}$ reported a series of similar ring-opening fluorination protocols for the synthesis of $\beta$ - and $\gamma$-fluorinated ketones

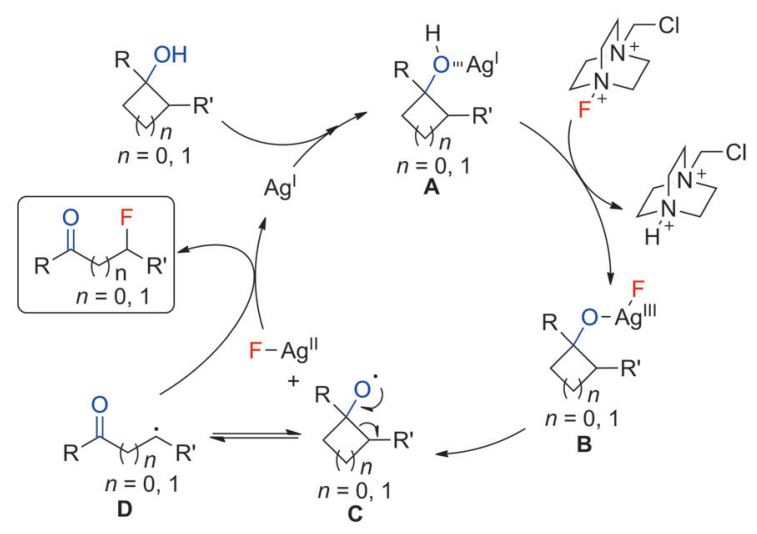

Scheme 19. Proposed mechanism of silver-catalyzed ring-opening fluorination of cyclopropanols and cyclobutanols.

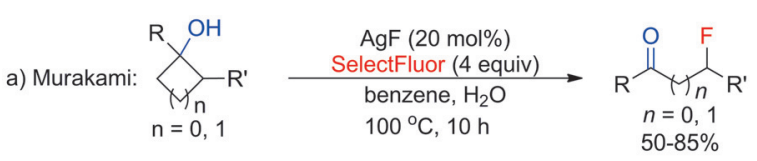

$$
\begin{aligned}
& \text { b) Loh: } \underbrace{\mathrm{R}^{1}}_{\mathrm{R}^{2}} \stackrel{\substack{\text { cat. (10 mol\%) } \\
\text { SelectFluor (2 equiv) }}}{\mathrm{DCM} / \mathrm{H}_{2} \mathrm{O}(1: 1)} \\
& \text { cat. }=\mathrm{AgNO}_{3} \text { or } \mathrm{Fe}(\mathrm{acac})_{3}
\end{aligned}
$$

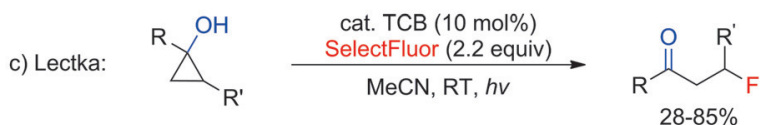

Scheme 20. Ring-opening fluorination of cyclic alcohols. TCB =1,2,4,5-tetracyanobenzene.
(Scheme 20). The major differences in these methods were the catalysts. Whereas $\mathrm{Ag}^{\prime}$ and $\mathrm{Fe}^{\mathrm{III}}$ salts were used as catalysts in Murakami's and Loh's protocols, Lectka presented an alternative procedure for the same transformation, namely, employing 1,2,4,5-tetracyanobenzene (TCB) as a single-electron transfer medium under photocatalytic conditions.

The ring-opening strategy could also be employed in the synthesis of distal fluoroalkyl ketones, some recent examples of which were reported by the groups of $\mathrm{Dai}_{1}^{[49]}$ Lopp $_{1}^{[50]}$ and $\mathrm{Xu}^{[51]}$ (Scheme 21). In Dai's method, both trifluoromethylation and trifluoromethylthiolation of cyclopropanols could be realized, although these reactions tended to take place at the less substituted carbons, in contrast to the previous fluorination re-
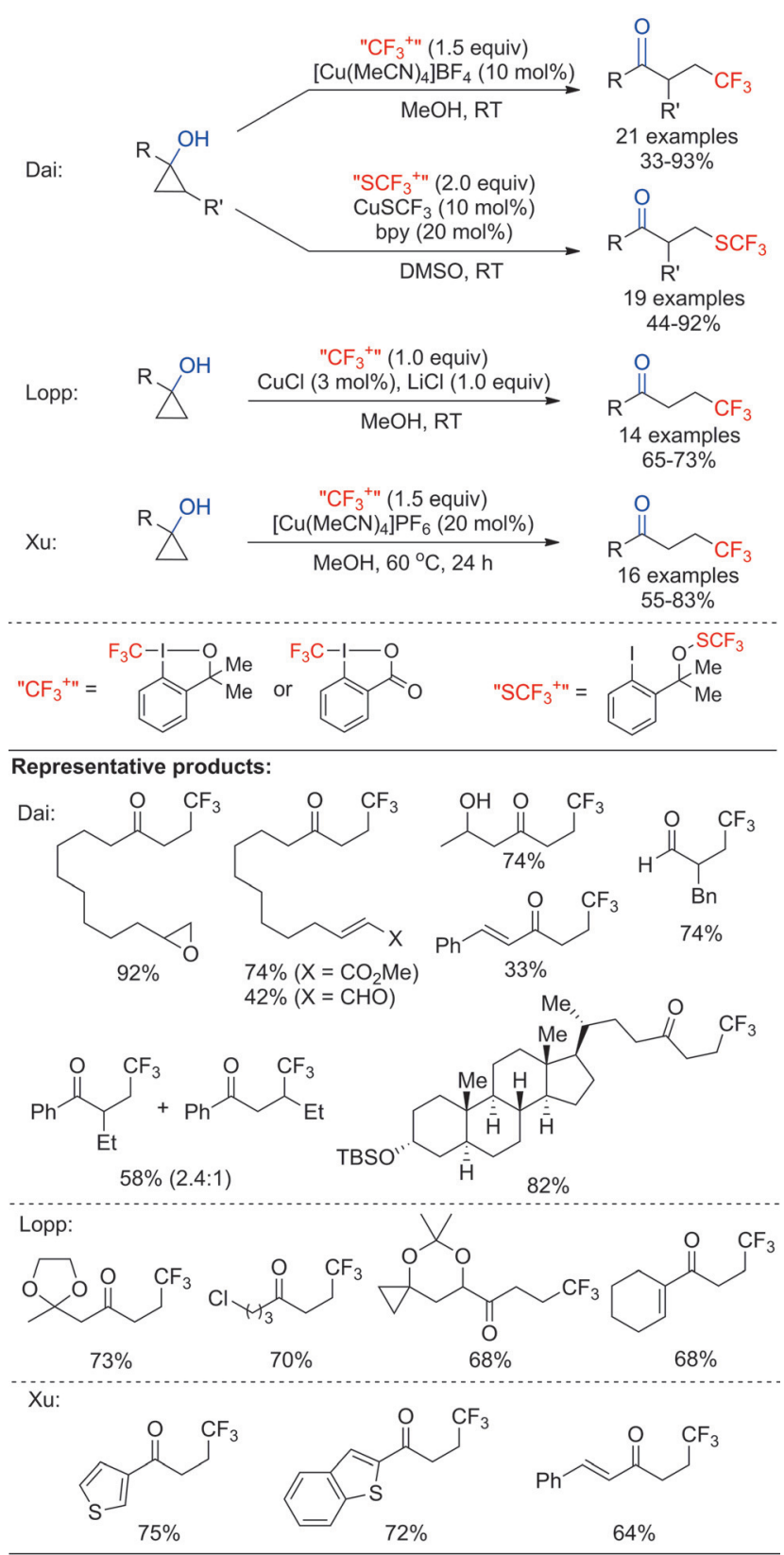

Scheme 21. Copper-catalyzed ring-opening trifluoromethylation/trifluoromethylthiolation of cyclopropanols. 


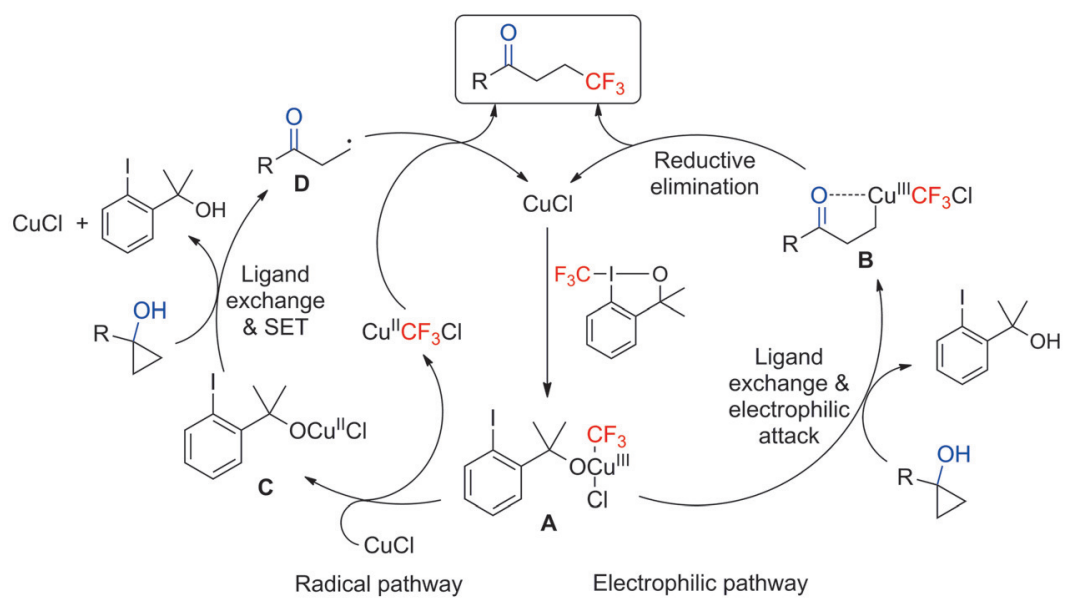

Scheme 22. Proposed mechanistic pathways leading to $\beta$-trifluoromethylated ketones.

actions. Notably, these reactions are very general and tolerate a wide range of functional groups (see Scheme 21 for examples).

Although mechanistic pictures of these transformations are not very clear at present, Lopp and co-workers proposed a hybrid mechanism, ${ }^{[50]}$ whereby both electrophilic and radical ring-opening pathways operate (Scheme 22 ). Initially, the reaction of $\mathrm{CuCl}$ with 3,3-dimethyl-1-(trifluoromethyl)-1,2-benziodoxole (Togni reagent) yields $\mathrm{Cu}^{\text {III }}$ complex $\mathbf{A}$, which undergoes ligand exchange with the cyclopropanol and followed by an electrophilic attack of the $\mathrm{Cu}^{\text {III }}$ center to generate a $\beta$-metalloketone intermediate $\mathbf{B}$. Reductive elimination of the intermediate $\mathbf{B}$ results in formation of the product and regeneration of the $\mathrm{CuCl}$ catalyst (Scheme 22, right). However, if the reaction of A with the cyclopropanol is not rapid enough (e.g. in the case of the more sterically hindered disubstituted cyclopropanols), it could react with $\mathrm{CuCl}$ and lose a $\mathrm{CF}_{3}$ ligand to produce a $\mathrm{Cu}^{\prime \prime}$ complex C. This complex converts the cyclopropanol into $\beta$-oxocarbonyl radical $\mathbf{D}$, which abstracts the $\mathrm{CF}_{3}$ group from the $\mathrm{Cu}^{\prime \prime} \mathrm{CF}_{3} \mathrm{Cl}$ to afford the final product and $\mathrm{CuCl}$ (Scheme 22, left).

In the case of 1,2-dialkyl-substituted cyclopropanols, a radical ring-opening pathway is known to proceed via $\beta$-keto radicals with selective cleavage of the $\mathrm{C} 1-\mathrm{C} 2$ bond, whereas the electrophilic ring-opening pathway predominantly gives rise to $\mathrm{C} 1-\mathrm{C} 3$ bond cleavage products. ${ }^{[416,52]}$ When enantiomerically enriched cyclopropanol cis-3 $\mathbf{a}^{[53]}$ was subjected to this ring cleavage reaction, the $\mathrm{C} 1-\mathrm{C} 2$ bond cleavage product $4 \mathrm{ab}$ was obtained in its racemic form, thus indicating the involvement of a $\beta$-keto radical intermediate (Scheme 23 ). Moreover, formation of this product was dramatically suppressed by the addition of 3,5-di-tert-butyl-4-hydroxytoluene (BHT), whereas the yield of $\mathrm{C} 1-\mathrm{C} 3$ cleavage product 4 aa remained almost unchanged. These results further supported the participation of both reaction pathways.

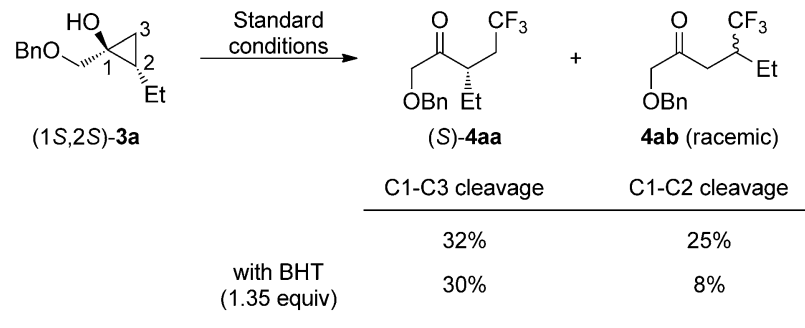

Scheme 23. Mechanistic studies of copper-catalyzed ring-opening trifluoromethylation of cyclopropanols.

\subsection{Nickel-catalyzed cross-trimerization of tetrafluoro- ethylene, ethylene, and carbonyl substrates}

Tetrafluoroethylene (TFE) is an industrial-grade organofluorine feedstock and it has been widely applied in the polymer industry. ${ }^{[54]}$ From a synthetic viewpoint, TFE could also be an ideal starting material in organic synthesis because it provides novel synthetic routes to complex fluorinated molecules that are otherwise difficult to access by conventional methods. ${ }^{[55]}$ Moreover, the $\mathrm{C}-\mathrm{F}$ bond activation of TFE by transition metal complexes could afford the corresponding organometallic complexes, ${ }^{[56]}$ which enables further transition metal-mediated cross-coupling reactions, such as the Negishi, ${ }^{[57]}$ SuzukiMiyaura, ${ }^{[58]}$ and Hiyama couplings. ${ }^{[59]}$ This activation-functionalization strategy could readily introduce a trifluoroethylene motif $\left(-\mathrm{CF}=\mathrm{CF}_{2}\right)$ into organic frameworks, yielding $(\alpha, \beta, \beta$-trifluoro)styrene derivatives.

Recently, Ohashi, Ogoshi, and co-workers reported an elegant strategy for incorporating a tetrafluoroethylene unit $\left(-\mathrm{CF}_{2} \mathrm{CF}_{2}-\right)$ at the remote position of ketones, without the loss of fluorine atoms (Scheme 24). ${ }^{[60]}$ Initially, the oxidative cyclization of TFE and ethylene with $\mathrm{Ni}^{0}$ afforded a five-membered nickelacycle intermediate. With the help of an auxiliary ligand $\left(\mathrm{PPh}_{3}\right)$, the partially fluorinated five-membered nickelacycle intermediate was isolated and characterized by X-ray analysis. This nickelacycle complex was found to be useful as it could 


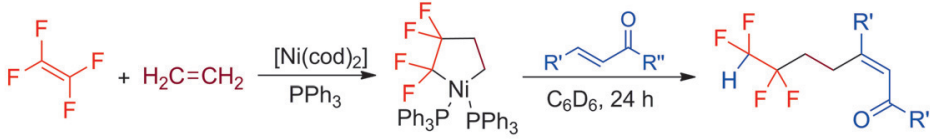

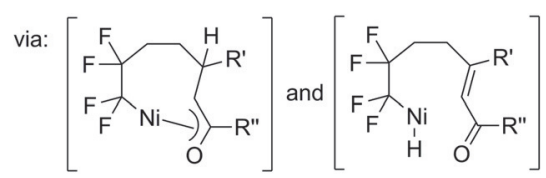

Scheme 24. Oxidative cyclization of tetrafluoroethylene and its application in fluorinated ketone synthesis.

undergo migratory insertion of enones into the $\mathrm{Ni}-\mathrm{CF}_{2}$ bond to give seven-membered nickelacycle intermediates. After $\beta$ hydride elimination and reductive elimination, these macrocyclic intermediates were converted into the corresponding $\beta$ substituted 6,6,7,7-tetrafluoroenones in $27-61 \%$ yield (isolated products). However, an attempt to develop a catalytic version of this cross-trimerization reaction failed, due to the formation of an inactive cyclization product from TFE and enones.

Shortly thereafter, another similar reaction, namely $\mathrm{Ni}^{0}$-catalyzed selective cross-trimerization of TFE, ethylene, and aldehydes, was reported by the same group (Scheme 25). ${ }^{[61]}$ By replacing $\alpha, \beta$-unsaturated ketones with aldehydes and employing the $\mathrm{N}$-heterocyclic carbene $(\mathrm{NHC})$ ligand $\mathrm{IPr}$, this reaction could proceed in the presence of a catalytic amount of $\left[\mathrm{Ni}(\operatorname{cod})_{2}\right](\operatorname{cod}=1,5$-cyclooctadiene). Both aromatic aldehydes and aliphatic aldehydes are good substrates for this trimerization reaction. However, aromatic aldehydes bearing halides such as $\mathrm{Cl}$ and $\mathrm{Br}$ were not tolerated in this reaction, probably due to the occurrence of undesired oxidative addition of the $\mathrm{C}-\mathrm{Cl}$ or $\mathrm{C}-\mathrm{Br}$ bond to $\mathrm{Ni}^{0}$ species. Moreover, sterically demanding groups were found to retard the reaction, thus the efficiency of o-tolualdehyde and mesitylaldehyde was diminished ( $62 \%$ and $15 \%$, respectively).

A mechanism was proposed for this novel cross-trimerization reaction (Scheme 26). As demonstrated in the previous

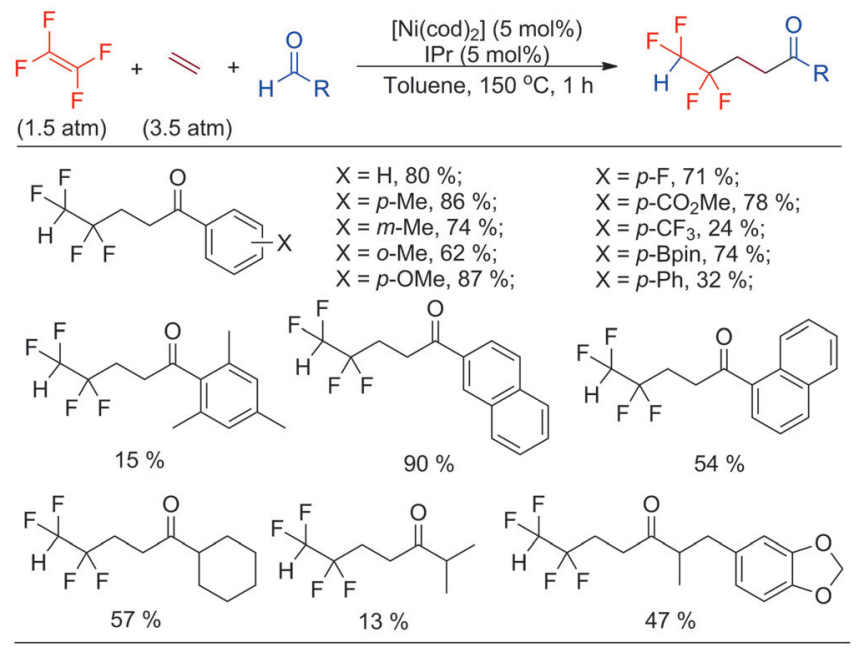

Scheme 25. Nickel-catalyzed cross-trimerization of tetrafluoroethylene, ethylene and aldehydes. study, ${ }^{[60]}$ the oxidative cyclization of TFE, ethylene, and $\mathrm{Ni}^{0}$ generates a 2,2,3,3-tetrafluoronickelacyclopentane species $\mathbf{A}$. This key intermediate undergoes nucleophilic addition to the carbonyl group to afford a seven-membered oxa-nickelacycle intermediate $\mathbf{B}$. Then, nickel hydride intermediate $\mathbf{C}$ would be generated through $\beta$-hydride elimination, before further undergoing reductive elimination to give the 4,4,5,5tetrafluoro-1-pentanone derivatives and regenerating the $\mathrm{Ni}^{0}$ catalyst.

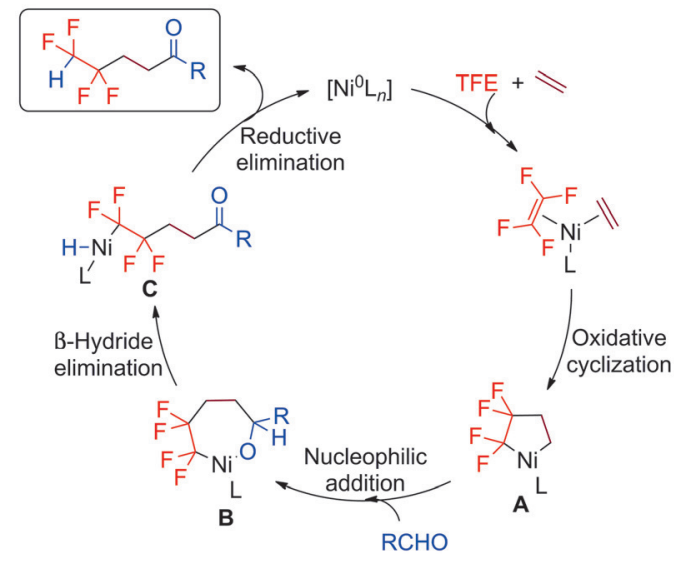

Scheme 26. Proposed mechanism of nickel-catalyzed formation of fluorinated ketones.

\section{Summary and Outlook}

The development of highly efficient methods for the preparation of complex fluorinated ketones is important in both synthetic chemistry and life sciences-related fields. In this Minireview, we have detailed significant recent advances in the synthesis of fluorinated ketones, especially highlighting those methods in which the construction of carbonyl groups is synergetic with incorporation of fluorine-containing groups. These strategically diverse protocols not only furnish various fluorinecontaining ketones in a single step, but are also suitable for the construction of distally fluorinated ketones. Furthermore, they provide excellent complements to the existing synthetic strategies.

Even though these methods have provided us with new approaches to complex fluorinated ketones which are otherwise difficult to synthesize by traditional routes, there is still much room for improvement. Because many reactions are limited in functional group compatibility, direct and efficient routes to natural product analogues are still highly needed. Furthermore, stereoselective formations of fluorinated ketones are generally absent from the existing method, this defect greatly retards their further application in synthetic chemistry.

To address these nontrivial problems, further innovations are required in designing new strategies, including late-stage modification of bioactive ketone molecules and transition metal-/organocatalyzed asymmetric formation of enantiopure fluorinated ketone compounds. We believe that this timely 
Minireview could stimulate further interest and open new ways to develop new methodologies in this field.

\section{Acknowledgements}

Support of our work by the National Basic Research Program of China (2015CB931900 and 2012CB821600), the NNSF of China (21372246, 21421002, 21302206 and 21402227), Shanghai City (15XD1504400) and the Chinese Academy of Sciences is gratefully acknowledged.

Keywords: fluorination - fluoroalkylation - ketones - one-pot synthesis - rearrangement

[1] a) P. Kirsch, Modern Fluoroorganic Chemistry, Wiley-VCH, Weinheim 2012; b) K. Uneyama, Organofluorine Chemistry, John Wiley \& Sons, 2008; c) S. Purser, P. R. Moore, S. Swallow, V. Gouverneur, Chem. Soc Rev. 2008, 37, 320-330; d) J. Wang, M. Sanchez-Rosello, J. L. Acena, C. del Pozo, A. E. Sorochinsky, S. Fustero, V. A. Soloshonok, H. Liu, Chem. Rev. 2014, 114, 2432-2506.

[2] For reviews, see: a) J.-P. Bégué, D. Bonnet-Delpon, Tetrahedron 1991, 47 3207-3258; b) C. B. Kelly, M. A. Mercadante, N. E. Leadbeater, Chem. Commun. 2013, 49, 11133-11148.

[3] a) I. P. Street, H. K. Lin, F. Laliberte, F. Ghomashchi, Z. Y. Wang, H. Perrier, N. M. Tremblay, Z. Huang, P. K. Weech, M. H. Gelb, Biochemistry 1993, 32, 5935-5940; b) P. R. Bernstein, B. C. Gomes, B. J. Kosmider, E. P. Vacek, J. C. Williams, J. Med. Chem. 1995, 38, 212-215; c) S. Chatterjee, M. A. Ator, D. Bozyczko-Coyne, K. Josef, G. Wells, R. Tripathy, M. Iqbal, R. Bihovsky, S. E. Senadhi, S. Mallya, T. M. O'Kane, B. A. McKenna, R. Siman, J. P. Mallamo, J. Med. Chem. 1997, 40, 3820-3828; d) D. L. Boger, H. Sato, A. E. Lerner, B. J. Austin, J. E. Patterson, M. P. Patricelli, B. F. Cravatt, Bioorg. Med. Chem. Lett. 1999, 9, 265-270; e) G. S. Garrett, S. J. McPhail, K. Tornheim, P. E. Correa, J. M. Mclver, Bioorg. Med. Chem. Lett. 1999, 9, $301-306$; f) R. R. Frey, C. K. Wada, R. B. Garland, M. L. Curtin, M. R. Michaelides, J. Li, L. J. Pease, K. B. Glaser, P. A. Marcotte, J. J. Bouska, S. S. Murphy, S. K. Davidsen, Bioorg. Med. Chem. Lett. 2002, 12, 3443-3447; g) V. Rodeschini, P. Van de Weghe, E. Salomon, C. Tarnus, J. Eustache, J. Org. Chem. 2005, 70, 2409-2412; h) M. Sani, R. Sinisi, F. Viani, Curr. Top. Med. Chem. 2006, 6, 1545-1566; i) D. M. Wallace, M. Haramura, J.-F. Cheng, T. Arrhenius, A. M. Nadzan, Bioorg. Med. Chem. Lett. 2007, 17, 1127-1130; j) Y.-M. Shao, W.-B. Yang, T.-H. Kuo, K.-C. Tsai, C.-H. Lin, A.-S. Yang, P.-H. Liang, C.-H. Wong, Bioorg. Med. Chem. 2008, 16, 4652-4660; k) J. Zhang, C. Huitema, C. Niu, J. Yin, M. N. G. James, L. D. Eltis, J. C. Vederas, Bioorg. Chem. 2008, 36, 229-240; I) J. Rayo, L. Muñoz, G. Rosell, B. Hammock, A. Guerrero, F. J. Luque, R. Pouplana, J. Mol. Model. 2010 16, $1753-1764 ;$ m) L. Muñoz, M. P. Bosch, L. Batllori, G. Rosell, D. Bosch, A. Guerrero, J. Avilla, Pest Manage. Sci. 2011, 67, 956-964; n) J.P. Doucet, A. Doucet-Panaye, J. Devillers, SAR QSAR Environ. Res. 2013, 24, $481-499$.

[4] a) D. Mead, R. Loh, A. E. Asato, R. S. H. Liu, Tetrahedron Lett. 1985, 26 2873-2876; b) R. Fernández, E. Martín-Zamora, C. Pareja, J. Vázquez, E. Díez, A. Monge, J. M. Lassaletta, Angew. Chem. Int. Ed. 1998, 37, 3428 3430; Angew. Chem. 1998, 110, 3598-3600; c) T. Ito, M. Shimizu, T. Fujisawa, Tetrahedron 1998, 54, 5523-5530; d) Y. Itoh, M. Yamanaka, K. Mikami, J. Am. Chem. Soc. 2004, 126, 13174-13175; e) V. Michaut, F. Metz, J.-M. Paris, J.-C. Plaquevent, J. Fluorine Chem. 2007, 128, 889-895; f) Y. Zhao, Y. Pan, H. Liu, Y. Yang, Z. Jiang, C.-H. Tan, Chem. Eur. J. 2011, $17,3571-3574$.

[5] a) Z.-M. Qiu, D. J. Burton, Tetrahedron Lett. 1994, 35, 4319-4322; b) L. M. Kacharova, I. I. Gerus, A. D. Kacharov, J. Fluorine Chem. 2002, 117, $193-$ 197; c) S. Buscemi, A. Pace, A. Palumbo Piccionello, N. Vivona, M. Pani, Tetrahedron 2006, 62, 1158-1164; d) N. Zanatta, J. M. F. M. Schneider, P. H. Schneider, A. D. Wouters, H. G. Bonacorso, M. A. P. Martins, L. A. Wessjohann, J. Org. Chem. 2006, 71, 6996-6998; e) J. Qian, W. Cao, H. Zhang, J. Chen, S. Zhu, J. Fluorine Chem. 2007, 128, 207-210; f) N. A. Tolmachova, I. I. Gerus, S. I. Vdovenko, G. Haufe, Y. A. Kirzhner, Synthesis
2007, 2007, 3797-3806; g) L. E. Kiss, H. S. Ferreira, D. A. Learmonth, Org. Lett. 2008, 10, 1835-1837; h) M. Yılmaz, Tetrahedron 2011, 67, 82558263 ; i) C. Christophe, B. R. Langlois, T. Billard, J. Fluorine Chem. 2013, 155, 118-123; j) B.-C. Zhao, Q.-Z. Zhang, W.-Y. Zhou, H.-C. Tao, Z.-G. Li, RSC Adv. 2013, 3, 13106-13109.

[6] a) J. T. Welch, Tetrahedron 1987, 43, 3123-3197; b) G. B. Dreyer, B.W. Metcalf, Tetrahedron Lett. 1988, 29, 6885-6888; c) M. E. Pierce, R. L. Parsons, L. A. Radesca, Y. S. Lo, S. Silverman, J. R. Moore, Q. Islam, A. Choudhury, J. M. D. Fortunak, D. Nguyen, C. Luo, S. J. Morgan, W. P. Davis, P. N. Confalone, C.-y. Chen, R. D. Tillyer, L. Frey, L. Tan, F. Xu, D. Zhao, A. S Thompson, E. G. Corley, E. J. J. Grabowski, R. Reamer, P. J. Reider, J. Org. Chem. 1998, 63, 8536-8543; d) F. Benayoud, A. Abouabdellah, C. Richard, D. Bonnet-Delpon, J.-P. Bégué, D. Levasseur, O. Boutaud, F. Schuber, Tetrahedron Lett. 2000, 41, 6367-6370; e) F. Grellepois, F. Chorki, B. Crousse, M. Ourévitch, D. Bonnet-Delpon, J.-P. Bégué, J. Org. Chem. 2002, 67, 1253-1260; f) M. Abid, B. Török, Adv. Synth. Catal. 2005, 347, 1797-1803; g) D. Riber, M. Venkataramana, S. Sanyal, T. Duvold, J. Med. Chem. 2006, 49, 1503-1505; h) J. T. Reeves, D. R. Fandrick, Z. Tan, J. J. Song, S. Rodriguez, B. Qu, S. Kim, O. Niemeier, Z. Li, D. Byrne, S. Campbell, A. Chitroda, P. DeCroos, T. Fachinger, V. Fuchs, N. C. Gonnella, N. Grinberg, N. Haddad, B. Jäger, H. Lee, J. C. Lorenz, S. Ma, B. A. Narayanan, L. J. Nummy, A. Premasiri, F. Roschangar, M. Sarvestani, S. Shen, E. Spinelli, X. Sun, R. J. Varsolona, N. Yee, M. Brenner, C. H. Senanayake, J. Org. Chem. 2013, 78, 3616-3635.

[7] C. H. Cheng, E. M. Pearce, J. Polym. Sci. Pol. Chem. 1980, 18, 1871-1876.

[8] R. J. Baker, T. McCabe, J. E. O'Brien, H. V. Ogilvie, J. Fluorine Chem. 2010, $131,621-626$.

[9] a) R. Mello, M. Fiorentino, C. Fusco, R. Curci, J. Am. Chem. Soc. 1989, 111, 6749-6757; b) A. Armstrong, B. R. Hayter, Chem. Commun. 1998, 621 622 ; c) D. Yang, Y.-C. Yip, J. Chen, K.-K. Cheung, J. Am. Chem. Soc. 1998, 120, 7659-7660; d) A. Armstrong, G. Ahmed, B. Dominguez-Fernandez, B. R. Hayter, J. S. Wailes, J. Org. Chem. 2002, 67, 8610-8617; e) S. E. Denmark, H. Matsuhashi, J. Org. Chem. 2002, 67, 3479-3486; f) C. J. Stearman, V. Behar, Tetrahedron Lett. 2002, 43, 1943-1946; g) A. Solladié-Cavallo, L. Jierry, A. Klein, M. Schmitt, R. Welter, Tetrahedron: Asymmetry 2004, 15, $3891-3898$.

[10] a) D. J. Burton, Z.-Y. Yang, Tetrahedron 1992, 48, 189-275; b) M. Yoshida, D. Suzuki, M. Iyoda, J. Chem. Soc. Perkin Trans. 1 1997, 643-648; c) R Kakino, I. Shimizu, A. Yamamoto, Bull. Chem. Soc. Jpn. 2001, 74, $371-$ 376; d) C. G. Kokotos, C. Baskakis, G. Kokotos, J. Org. Chem. 2008, 73, 8623-8626; e) D. Yang, Y. Zhou, N. Xue, J. Qu, J. Org. Chem. 2013, 78, 4171-4176; f) D. M. Rudzinski, C. B. Kelly, N. E. Leadbeater, Chem. Commun. 2012, 48, 9610-9612.

[11] a) R. J. Linderman, D. M. Graves, Tetrahedron Lett. 1987, 28, 4259-4262; b) R. J. Linderman, D. M. Graves, J. Org. Chem. 1989, 54, 661-668; c) V. Kesavan, D. Bonnet-Delpon, J. P. Begue, A. Srikanth, S. Chandrasekaran, Tetrahedron Lett. 2000, 41, 3327-3330; d) C. B. Kelly, M. A. Mercadante, T. A. Hamlin, M. H. Fletcher, N. E. Leadbeater, J. Org. Chem. 2012, 77, 8131-8141; e) Y. Tanaka, T. Ishihara, T. Konno, J. Fluorine Chem. 2012, 137, 99-104; f) H. Cheng, Y. Pei, F. Leng, J. Li, A. Liang, D. Zou, Y. Wu, Y. Wu, Tetrahedron Lett. 2013, 54, 4483-4486; g) Y. Kadoh, M. Tashiro, K. Oisaki, M. Kanai, Adv. Synth. Catal. 2015, 357, 2193-2198.

[12] a) P. M. Pihko, Angew. Chem. Int. Ed. 2006, 45, 544-547; Angew. Chem. 2006, 118, 558-561; b) P. V. Pham, D. A. Nagib, D. W. C. MacMillan, Angew. Chem. Int. Ed. 2011, 50, 6119-6122; Angew. Chem. 2011, 123 $6243-6246$; c) P. Novák, A. Lishchynskyi, V. V. Grushin, J. Am. Chem. Soc. 2012, 134, 16167-16170; d) T. Kitamura, K. Muta, K. Muta, J. Org. Chem. 2014, 79, 5842-5846; e) Y. Wang, Y. You, Z. Weng, J. Fluorine Chem. 2015, 175, $51-59$

[13] a) J.-P. Bégué, D. Mesureur, Synthesis 1989, 309-312; b) A. Thenappan, D. J. Burton, J. Org. Chem. 1991, 56, 273-277; c) J. P. Begue, D. Bonnetdelpon, D. Mesureur, G. Nee, S. W. Wu, J. Org. Chem. 1992, 57, $3807-$ 3814.

[14] a) T. Keumi, M. Shimada, M. Takahashi, H. Kitajima, Chem. Lett. 1990 $783-786$; b) M. Hojo, R. Masuda, S. Sakaguchi, M. Takagawa, Synthesis 1986, 1016- 1017.

[15] a) B. W. Metcalf, E. T. Jarvi, J. P. Burkhart, Tetrahedron Lett. 1985, 26, 2861-2864; b) E. Bélanger, C. Houze, N. Guimond, K. Cantin, J.-F. Paquin, Chem. Commun. 2008, 3251-3253; c) T. Luo, R. Zhang, W. Zhang, X. Shen, T. Umemoto, J. Hu, Org. Lett. 2014, 16, 888-891; d) T.-P. Yang, Q. Li, J.-H. Lin, J.-C. Xiao, Chem. Commun. 2014, 50, 1077-1079; 
e) M. D. Kosobokov, V. V. Levin, M. I. Struchkova, A. D. Dilman, Org. Lett 2015, 17, 760-763; f) X. Song, J. Chang, D. Zhu, J. Li, C. Xu, Q. Liu, M. Wang, Org. Lett. 2015, 17, 1712-1715; g) T. Luo, R. Zhang, X. Shen, W. Zhang, C. Ni, J. Hu, Dalton Trans. 2015, 44, 19636-19641.

[16] a) W. Wang, J. Jasinski, G. B. Hammond, B. Xu, Angew. Chem. Int. Ed. 2010, 49, 7247-7252; Angew. Chem. 2010, 122, 7405-7410; b) A. Deb S. Manna, A. Modak, T. Patra, S. Maity, D. Maiti, Angew. Chem. Int. Ed. 2013, 52, 9747-9750; Angew. Chem. 2013, 125, 9929-9932; c) Z. He, R. Zhang, M. Hu, L. Li, C. Ni, J. Hu, Chem. Sci. 2013, 4, 3478-3483; d) L. Li, Q.-Y. Chen, Y. Guo, J. Org. Chem. 2014, 79, 5145-5152.

[17] a) G. K. S. Prakash, A. K. Yudin, Chem. Rev. 1997, 97, 757-786; b) R. P. Singh, R. L. Kirchmeier, J. M. Shreeve, Org. Lett. 1999, 1, 1047-1049; c) T. Billard, S. Bruns, B. R. Langlois, Org. Lett. 2000, 2, 2101-2103; d) S Mizuta, N. Shibata, T. Sato, H. Fujimoto, S. Nakamura, T. Toru, Synlett 2006, 267-270; e) T. Billard, B. R. Langlois, Eur. J. Org. Chem. 2007, $891-$ 897; f) J. A. Ma, D. Cahard, Chem. Rev. 2008, 108, PR1-PR43; g) N. Shibata, S. Mizuta, H. Kawai, Tetrahedron: Asymmetry 2008, 19, $2633-2644$ h) T. Besset, T. Poisson, X. Pannecoucke, J. Fluorine Chem. 2015, 178, $225-240$.

[18] For 1,4-nucleophilic trifluoromethylation of special substrates, see: a) D. V. Sevenard, V. Y. Sosnovskikh, A. A. Kolomeitsev, M. H. Konigsmann, G. V. Roschenthaler, Tetrahedron Lett. 2003, 44, 7623-7627 b) V. Y. Sosnovskikh, B. I. Usachev, D. V. Sevenard, G. V. Roschenthaler, J. Org. Chem. 2003, 68, 7747-7754; c) C.-L. Wang, H.-Q. Li, W.-D. Meng, F.L. Qing, Bioorg. Med. Chem. Lett. 2005, 15, 4456-4458; d) A. D. Dilman V. V. Levin, P. A. Belyakov, M. I. Struchkova, V. A. Tartakovsky, Tetrahedron Lett. 2008, 49, 4352-4354; e) A. A. Zemtsov, V. V. Levin, A. D. Dilman, M. I. Struchkova, P. A. Belyakov, V. A. Tartakovsky, Tetrahedron Lett. 2009 50, 2998-3000; for directing-group-assisted copper-catalyzed trifluoromethylation of $\alpha, \beta$-unsaturated amides, see: $f) C$. Feng, T.-P. Loh, Angew. Chem. Int. Ed. 2013, 52, 12414-12417; Angew. Chem. 2013, 125, $12640-$ 12643.

[19] S. Okusu, Y. Sugita, E. Tokunaga, N. Shibata, Beilstein J. Org. Chem. 2013, 9, 2189-2193.

[20] a) T. J. Snape, Chem. Soc. Rev. 2007, 36, 1823-1842; b) F. Kleinbeck, F. D. Toste, J. Am. Chem. Soc. 2009, 131, 9178-9179; c) Z.-M. Chen, Q.-W. Zhang, Z.-H. Chen, H. Li, Y.-Q. Tu, F.-M. Zhang, J.-M. Tian, J. Am. Chem Soc. 2011, 133, 8818-8821; d) B. Wang, Y. Tu, Acc. Chem. Res. 2011, 44 1207-1222; e) Z. Chai, T. J. Rainey, J. Am. Chem. Soc. 2012, 134, $3615-$ 3618.

[21] For reviews of aromatic $C-C$ ipso-substitution reactions, see: a) A. Studer, M. Bossart, Tetrahedron 2001, 57, 9649-9667; b) S. M. Bonesi, M. Fagnoni, Chem. Eur. J. 2010, 16, 13572-13589; for selectivity of neophyl rearrangement, see: c) C. S. Aureliano Antunes, M. Bietti, G. Ercolani, O. Lanzalunga, M. Salamone, J. Org. Chem. 2005, 70, 3884-3891.

[22] For selectivity of semipinacol rearrangement, see: L. Li, P. Cai, Q. Guo, S. Xue, J. Org. Chem. 2008, 73, 3516-3522.

[23] a) X. Liu, F. Xiong, X. Huang, L. Xu, P. Li, X. Wu, Angew. Chem. Int. Ed. 2013, 52, 6962-6966; Angew. Chem. 2013, 125, 7100-7104; b) Z.-M. Chen, W. Bai, S.-H. Wang, B.-M. Yang, Y.-Q. Tu, F.-M. Zhang, Angew. Chem. Int. Ed. 2013, 52, 9781-9785; Angew. Chem. 2013, 125, $9963-$ 9967.

[24] Other similar examples of trifluoromethylation-initiated 1,2-migration of allylic alcohols, see: a) H. Egami, R. Shimizu, Y. Usui, M. Sodeoka, Chem. Commun. 2013, 49, 7346-7348; b) H.-L. Huang, H. Yan, G.-L. Gao, C. Yang, W. Xia, Asian J. Org. Chem. 2015, 4, 674-677; c) S. B. Woo, D. Y. Kim, J. Fluorine Chem. 2015, 178, 214-218.

[25] For selected examples, see: a) R. D. Chambers, M. Parsons, S. A. Graham, R. Bowden, Chem. Commun. 2000, 959-960; b) J. A. Miller, G. M. Ullah, G. M. Welsh, P. Mallon, Tetrahedron Lett. 2001, 42, 2729-2731.

[26] M. Wang, B. M. Wang, L. Shi, Y. Q. Tu, C.-A. Fan, S. H. Wang, X. D. Hu, S. Y. Zhang, Chem. Commun. 2005, 5580-5582.

[27] Z.-M. Chen, B.-M. Yang, Z.-H. Chen, Q.-W. Zhang, M. Wang, Y.-Q. Tu, Chem. Eur. J. 2012, 18, 12950-12954.

[28] a) Q.-Y. Chen, S.-W. Wu, J. Chem. Soc. Chem. Commun. 1989, 705-706; b) Q.-Y. Chen, G.-Y. Yang, S.-W. Wu, J. Fluorine Chem. 1991, 55, $291-298$; c) D.-B. Su, J.-X. Duan, Q.-Y. Chen, Tetrahedron Lett. 1991, 32, 1541; d) M. Huiban, M. Tredwell, S. Mizuta, Z. Wan, X. Zhang, T. L. Collier, V. Gouverneur, J. Passchier, Nat. Chem. 2013, 5, $941-944$.

[29] B. Gao, Y. Zhao, J. Hu, Angew. Chem. Int. Ed. 2015, 54, 638-642; Angew. Chem. 2015, 127, 648-652.
[30] B. Gao, Y. Zhao, C. Ni, J. Hu, Org. Lett. 2014, 16, 102-105.

[31] a) G. Zhang, Y. Peng, L. Cui, L. Zhang, Angew. Chem. Int. Ed. 2009, 48, 3112-3115; Angew. Chem. 2009, 121, 3158-3161; b) B. S. L. Collins, M. G. Suero, M. J. Gaunt, Angew. Chem. Int. Ed. 2013, 52, 5799-5802; Angew. Chem. 2013, 125, 5911-5914; c) M. Yu, G. Zhang, L. Zhang, Org. Lett. 2007, 9, 2147-2150; d) T. de Haro, C. Nevado, Chem. Commun. $2011,47,248-249$

[32] Y.-P. Xiong, M.-Y. Wu, X.-Y. Zhang, C.-L. Ma, L. Huang, L.-J. Zhao, B. Tan X.-Y. Liu, Org. Lett. 2014, 16, 1000-1003.

[33] S. Park, J. M. Joo, E. J. Cho, Eur. J. Org. Chem. 2015, 2015, 4093-4097.

[34] For reviews, see: a) M. G. Campbell, T. Ritter, Chem. Rev. 2015, 115, 612 633 ; b) Y. Li, Y. Wu, G.-S. Li, X.-S. Wang, Adv. Synth. Catal. 2014, 356, $1412-1418$.

[35] For selected examples, see: a) T. J. Barker, D. L. Boger, J. Am. Chem. Soc 2012, 134, 13588-13591; b) Z. Li, L. Song, C. Li, J. Am. Chem. Soc. 2013, 135, 4640-4643; c) H. Shigehisa, E. Nishi, M. Fujisawa, K. Hiroya, Org Lett. 2013, 15, 5158-5161; d) C. Zhang, Z. Li, L. Zhu, L. Yu, Z. Wang, C. Li, J. Am. Chem. Soc. 2013, 135, 14082-14085; e) Z. Li, C. Zhang, L. Zhu, C. Liu, C. Li, Org. Chem. Front. 2014, 1, 100-104; f) S. Mizuta, I. S. R. Stenhagen, M. O'Duill, J. Wolstenhulme, A. K. Kirjavainen, S. J. Forsback M. Tredwell, G. Sandford, P. R. Moore, M. Huiban, S. K. Luthra, J. Passchier, O. Solin, V. Gouverneur, Org. Lett. 2013, 15, 2648-2651; g) J. C. T. Leung, C. Chatalova-Sazepin, J. G. West, M. Rueda-Becerril, J. F. Paquin, G. M. Sammis, Angew. Chem. Int. Ed. 2012, 51, 10804-10807; Angew. Chem. 2012, 124, 10962-10965; h) M. Rueda-Becerril, O. Mahe, M. Drouin, M. B. Majewski, J. G. West, M. O. Wolf, G. M. Sammis, J. F. Paquin, J. Am. Chem. Soc. 2014, 136, 2637-2641; i) S. Bloom, C. R. Pitts, D. C. Miller, N. Haselton, M. G. Holl, E. Urheim, T. Lectka, Angew. Chem. Int. Ed. 2012, 51, 10580-10583; Angew. Chem. 2012, 124, 10732-10735; j) W. Liu, J. T. Groves, Angew. Chem. Int. Ed. 2013, 52, 6024-6027; Angew. Chem. 2013, 125, 6140-6143; k) J.-B. Xia, C. Zhu, C. Chen, J. Am. Chem. Soc. 2013, 135, 17494-17500.

[36] H. Wang, L.-N. Guo, X.-H. Duan, Chem. Commun. 2014, 50, 7382-7384

[37] a) J. M. Anderson, J. K. Kochi, J. Am. Chem. Soc. 1970, 92, 1651-1659; b) J. M. Anderson, J. K. Kochi, J. Org. Chem. 1970, 35, 986-989.

[38] F. Yin, Z. Wang, Z. Li, C. Li, J. Am. Chem. Soc. 2012, 134, 10401-10404.

[39] L. Zhu, H. Chen, Z. Wang, C. Li, Org. Chem. Front. 2014, 1, 1299-1305.

[40] B. Schweitzer-Chaput, J. Demaerel, H. Engler, M. Klussmann, Angew. Chem. Int. Ed. 2014, 53, 8737-8740; Angew. Chem. 2014, 126, $8882-$ 8885.

[41] a) O. G. Kulinkovich, A. de Meijere, Chem. Rev. 2000, 100, 2789-2834; b) O. G. Kulinkovich, Chem. Rev. 2003, 103, 2597-2632; c) A. Wolan, Y. Six, Tetrahedron 2010, 66, 15-61.

[42] a) P. P. Das, K. Belmore, J. K. Cha, Angew. Chem. Int. Ed. 2012, 51, $9517-$ 9520; Angew. Chem. 2012, 124, 9655-9658; b) D. Rosa, A. Orellana, Chem. Commun. 2013, 49, 5420-5422.

[43] a) Y.-F. Wang, S. Chiba, J. Am. Chem. Soc. 2009, 131, 12570-12572; b) A. llangovan, S. Saravanakumar, S. Malayappasamy, Org. Lett. 2013, 15, 4968-4971; c) S. Chiba, Z. Y. Cao, S. A. A. El Bialy, K. Narasaka, Chem. Lett. 2006, 35, 18-19.

[44] J. Jiao, L. X. Nguyen, D. R. Patterson, R. A. Flowers, Org. Lett. 2007, 9, $1323-1326$.

[45] H. Zhao, X. Fan, J. Yu, C. Zhu, J. Am. Chem. Soc. 2015, 137, 3490-3493.

[46] N. Ishida, S. Okumura, Y. Nakanishi, M. Murakami, Chem. Lett. 2015, 44, $821-823$

[47] S. Bloom, D. D. Bume, C. R. Pitts, T. Lectka, Chem. Eur. J. 2015, 21, 8060 8063.

[48] S. Ren, C. Feng, T.-P. Loh, Org. Biomol. Chem. 2015, 13, 5105-5109.

[49] Y. Li, Z. Ye, T. M. Bellman, T. Chi, M. Dai, Org. Lett. 2015, 17, 2186-2189.

[50] D. G. Kananovich, Y. A. Konik, D. M. Zubrytski, I. Jarving, M. Lopp, Chem. Commun. 2015, 51, 8349-8352.

[51] X.-P. He, Y.-J. Shu, J.-J. Dai, W.-M. Zhang, Y.-S. Feng, H.-J. Xu, Org. Biomol. Chem. 2015, 13, 7159-7163.

[52] D. H. Gibson, C. H. Depuy, Chem. Rev. 1974, 74, 605-623.

[53] O. G. Kulinkovich, D. G. Kananovich, M. Lopp, V. Snieckus, Adv. Synth. Catal. 2014, 356, 3615-3626.

[54] B. Ameduri, B. Boutevin, J. Fluorine Chem. 2000, 104, 53-62.

[55] a) S. Dixon, J. Org. Chem. 1956, 21, 400-403; b) G. D. Crouse, J. D. Webster, J. Org. Chem. 1992, 57,6643-6646; c) A. C. Sievert, W. R. Tong, M. J. Nappa, J. Fluorine Chem. 1991, 53, 397-417; d) V. A. Petrov, S. Swearingen, W. P. Hong, W. C. Petersen, J. Fluorine Chem. 2001, 109, 25-31; 
e) V. V. Rudyuk, D. V. Fedyuk, L. A. Yagupolskii, J. Fluorine Chem. 2004, $125,1465-1471$.

[56] a) M. J. Hacker, L. Gw, R. D. W. Kemmitt, J. Organomet. Chem. 1973, 47, 189-193; b) J. A. K. Howard, S. A. R. Knox, N. J. Terrill, M. I. Yates, J. Chem. Soc. Chem. Commun. 1989, 640-642; c) D. J. Anderson, R. McDonald, M. Cowie, Angew. Chem. Int. Ed. 2007, 46, 3741-3744; Angew. Chem. 2007, 119, 3815-3818.

[57] a) M. Ohashi, T. Kambara, T. Hatanaka, H. Saijo, R. Doi, S. Ogoshi, J. Am. Chem. Soc. 2011, 133, 3256-3259; b) M. Ohashi, M. Shibata, H. Saijo, T. Kambara, S. Ogoshi, Organometallics 2013, 32, 3631-3639.

[58] M. Ohashi, H. Saijo, M. Shibata, S. Ogoshi, Eur. J. Org. Chem. 2013, $443-$ 447.
[59] H. Saijo, H. Sakaguchi, M. Ohashi, S. Ogoshi, Organometallics 2014, 33, 3669-3672.

[60] M. Ohashi, T. Kawashima, T. O. Taniguchi, K. Kikushima, S. Ogoshi, Organometallics 2015, 34, 1604-1607.

[61] M. Ohashi, H. Shirataki, K. Kikushima, S. Ogoshi, J. Am. Chem. Soc. 2015, 137, 6496-6499.

Received: October 8, 2015

Published online on December 22, 2015 